\title{
T cell response kinetics determines neuroinfection outcomes during murine HSV infection
}

\author{
Aisha G. Lee, ${ }^{1}$ Jason M. Scott, ${ }^{1}$ Maria Rita Fabbrizi, ${ }^{1}$ Xiaoping Jiang, ${ }^{1}$ Dorothy K. Sojka, ${ }^{2}$ \\ Mark J. Miller, ${ }^{1}$ Megan T. Baldridge, ${ }^{1}$ Wayne M. Yokoyama, ${ }^{2}$ and Haina Shin ${ }^{1}$ \\ 'Division of Infectious Diseases and 2Division of Rheumatology, Department of Medicine, Washington University School of \\ Medicine, St. Louis, Missouri, USA.
}

\begin{abstract}
Herpes simplex virus-2 (HSV-2) and HSV-1 both can cause genital herpes, a chronic infection that establishes a latent reservoir in the nervous system. Clinically, the recurrence frequency of HSV-1 genital herpes is considerably less than HSV-2 genital herpes, which correlates with reduced neuronal infection. The factors dictating the disparate outcomes of HSV-1 and HSV-2 genital herpes are unclear. In this study, we show that vaginal infection of mice with HSV-1 leads to the rapid appearance of mature DCs in the draining lymph node, which is dependent on an early burst of NK cell-mediated IFN- $\gamma$ production in the vagina that occurs after HSV- 1 infection but not HSV-2 infection. Rapid DC maturation after HSV-1 infection, but not HSV-2 infection, correlates with the accelerated generation of a neuroprotective $\mathrm{T}$ cell response and early accumulation of IFN- $\gamma-$ producing T cells at the site of infection. Depletion of T cells or loss of IFN- $\gamma$ receptor (IFN- $\gamma \mathrm{R}$ ) expression in sensory neurons both lead to a marked loss of neuroprotection only during HSV-1, recapitulating a prominent feature of HSV-2 infection. Our experiments reveal key differences in host control of neuronal HSV-1 and HSV-2 infection after genital exposure of mice, and they define parameters of a successful immune response against genital herpes.
\end{abstract}

Conflict of interest: The authors have declared that no conflict of interest exists.

Copyright: (ㄷ) 2020, American Society for Clinical Investigation.

Submitted: October 14, 2019

Accepted: February 12, 2020

Published: March 12, 2020.

Reference information: /CI Insight. 2020;5(5):e134258

https://doi.org/10.1172/jci. insight.134258.

\section{Introduction}

Genital herpes is a chronic, sexually transmitted infection that causes significant morbidity globally. Genital herpes is primarily caused by herpes simplex virus-2 (HSV-2), a double-stranded DNA virus of the alphaherpesvirus family, and there are over 400 million people affected (1). Upon transmission, the virus invades genital epithelial cells and spreads into sensory neurons of the dorsal root ganglia (DRG). Within sensory neurons, HSV-2 enters latency and persists in a relatively quiescent state. Periodically, the virus reactivates, leading to viral shedding and the recurrent ulcers characteristic of genital herpes. Once a latent reservoir is established, the host is unable to completely clear the virus, and the infection becomes chronic. Thus, understanding the factors that control neuronal infection is vital to preventing chronic disease.

HSV-1, an alphaherpesvirus that is highly related to HSV-2, is typically associated with infection of oral mucocutaneous tissues and the development of cold sores. However, the last few decades have seen a rise in the number of genital herpes cases that are caused by HSV-1. An estimated 140 million people have HSV-1 genital herpes, and in developed parts of the Western world, HSV-1 has overtaken HSV-2 as the cause of genital herpes infections (2-4). Despite a high level of similarity in tissue tropism and pathogenesis between the viruses, HSV-1 causes milder genital disease after sexual transmission than HSV-2 and is better controlled by the host (5-7). Recurrence rates of HSV-1 genital herpes are approximately $20 \%$ of HSV-2 recurrence rates $(6,7)$, with HSV-1 recurrence dropping rapidly within 2 years of primary infection (7). Currently, the biological basis of the difference in reactivation frequency of HSV-1- and HSV-2-mediated genital disease remains unclear.

Animal studies have shown that the establishment of HSV-1 and HSV-2 infection in the nervous system is a key factor in determining recurrent disease outcomes (8-10). Reactivation frequency does not correlate with viral replication competence at mucosal barriers during primary infection, as HSV-1 and HSV-2 both replicate robustly at multiple sites of entry $(8,9,11)$. Instead, vaginal infection of guinea pigs demonstrates a direct relationship between the quantity of viral genomes and latency associated transcripts (LAT) with 
reactivation rates (11-14). Equal amounts of HSV-1 and HSV-2 inoculum resulted in less viral DNA and less LAT expression in the ganglia of HSV-1-infected guinea pigs, which correlated with less frequent reactivation, despite similar levels of viral replication in the genital mucosa (11). Increasing the HSV-1 inoculum dose to augment viral DNA levels in the DRG resulted in the equalization of recurrence rates (11), suggesting that reduced reactivation frequency after HSV-1 is mainly due to fewer viral genomes in the ganglia, as opposed to an inherent inability of HSV-1 to infect the genital tract and cause local disease. It is unclear whether the HSV-1 reservoir in the DRG is consistently smaller than HSV-2 due to defects in replication within the neuron or other virus-intrinsic features regulating latency establishment or whether it is a consequence of distinct host responses against these 2 related viruses.

Adaptive immune responses - particularly $\mathrm{T}$ cell responses - are critical for controlling genital HSV infection. Virus-specific T cells can be found within active and quiescent lesions of infected patients (1517), and $\mathrm{T}$ cell density is predicted to inversely correlate with symptomatic recurrences (18-20). Animal studies suggest a division of labor between $\mathrm{CD}^{+}$and $\mathrm{CD}^{+} \mathrm{T}$ cells in response to genital HSV challenge. IFN- $\gamma$-producing memory $\mathrm{CD}^{+}{ }^{+} \mathrm{T}$ cells are primarily responsible for eliminating mucosal viral replication (21-24), although memory CD4 ${ }^{+} \mathrm{T}$ cells can also provide neuroprotection through an antibody-dependent mechanism (25). In contrast, memory $\mathrm{CD}^{+} \mathrm{T}$ cells provide neuroprotection and suppress viral reactivation through various effector mechanisms (26-29). The role of T cells during primary HSV infection - particularly their role in shaping the neuronal reservoir after HSV-1 or HSV-2 infection - is less clear.

To begin addressing the question as to whether the host response accounts for the differences in neuronal infection during primary HSV-1 and HSV-2 infection, we examined early innate responses in the vagina and T cell responses against these 2 viruses using a mouse model of infection. Vaginal infection with HSV-1, but not HSV-2, resulted in the early appearance of mature DCs in the draining lymph node (dLN), as well as rapid activation and dissemination of IFN- $\gamma$-producing T cells. Maturation of DCs after HSV-1 infection was dependent upon rapid production of NK-cell dependent IFN- $\gamma$ in the vagina 1 day postinfection (d.p.i.), which did not occur after HSV-2 infection. Accordingly, protection of the peripheral nervous system from HSV-1 infection was dependent on both T cells and neuronal responsiveness to IFN- $\gamma$. Our results highlight unexpected differences in the primary immune response against these 2 related viruses and begin to reveal host factors that may contribute to disparities in recurrence frequency between HSV-1 and HSV-2 genital herpes.

\section{Results}

Vaginal infection with HSV-1 leads to less nervous system infection and milder disease than HSV-2. To dissect the host responses against genital HSV-1 and HSV-2 infection, female C57BL/6J mice were first injected with depot medroxyprogesterone (DMPA, Depo-Provera) to arrest the mice in their estrus cycle and enhance susceptibility to viral infection (30). Mice were then intravaginally inoculated with $1 \times$ $10^{4}$ plaque forming units (PFUs) of HSV-2 strain 186 syn $^{+}$and HSV-1 strain McKrae, which is highly neurovirulent compared with other HSV-1 strains $(31,32)$. Viral shedding into the vaginal lumen was similar between HSV-1- and HSV-2-infected mice during the first 5 days of infection, with a small but significant increase in HSV-2 shedding observed on day 6 (Figure 1A). As expected, viral burden in the lumbar-sacral DRG at this time point, which was chosen as the latest time point before HSV-2-infected mice began to display signs of morbidity, was substantially lower in mice infected with HSV-1 as compared with HSV-2 (Figure 1B). Remarkably, 45\% of the HSV-1-infected mice had ganglia titers that were below the limit of detection, despite robust viral shedding in the vaginal mucosa. As expected, HSV-1-infected mice also displayed milder genital inflammation compared with HSV-2-infected mice (Supplemental Figure 1A; supplemental material available online with this article; https://doi. org/10.1172/jci.insight.134258DS1). Accordingly, less damage in the mucosa was present after HSV-1 infection compared with HSV-2 infection (Supplemental Figure 1B). None of the HSV-1-infected mice developed signs of neuro-invasive disease, and all mice survived, in contrast to the low survival rate of HSV-2-infected animals (Supplemental Figure 1C). Although we were unable to assess latency due to the high mortality rate of the HSV-2-infected group, measurement of viral genomes in the ganglia by quantitative PCR (qPCR) at 6 d.p.i. directly correlated with the load of replicating virus (Supplemental Figure 2), suggesting that HSV-1 infection would have resulted in a small latent reservoir. Together, our data confirm previous studies $(8,9,11)$ that have reported decreased disease severity and ganglion titers after HSV-1 infection compared with HSV-2 infection, and they establish a model in which to interrogate host responses that regulate neuronal infection by HSV. 
A

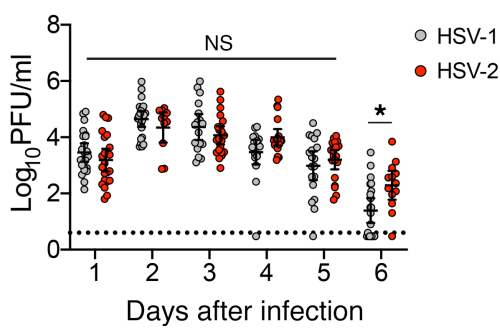

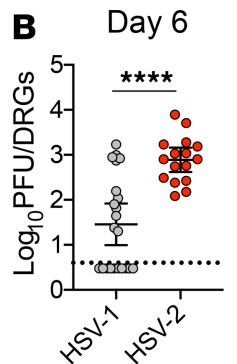

Figure 1. Vaginal HSV-1 infection leads to lower viral burden in the dorsal root ganglia compared with HSV-2 infection. Eight-week-old [57BL/6] mice were injected with Depo-Provera and inoculated intravaginally with 1 $\times 10^{4}$ PFU HSV-1 strain McKrae or HSV-2 strain $186 \mathrm{syn}^{+}$. (A) Vaginal washes were collected from mice daily after infection, and replicating virus was measured by plaque assay (HSV-1, $n=17-23$; HSV-2, $n=13-22$ ). (B) Ganglia were harvested from HSV-1- or HSV-2-infected mice at 6 days postinfection (d.p.i) (HSV-1, $n=22$; HSV-2, $n=16$ ). Dashed lines in $\mathbf{A}$ and $\mathbf{B}$ show limit of detection. Data in $\mathbf{A}$ and $\mathbf{B}$ are pooled from at least $\mathbf{3}$ independent experiments. Horizontal bars show mean, vertical lines show $95 \% \mathrm{Cl}$. Statistical significance in A was measured by 2-way ANOVA with Bonferroni multiple comparisons test on log-transformed data. Statistical significance in B was measured by Mann-Whitney $U$ test on log-transformed data. ${ }^{* * * *} P<0.001$.

Greater numbers of mature DCs are present in the dLN after vaginal HSV-1 infection. Due to the importance of T cells in neuroprotection after HSV infection $(25,26)$, we first evaluated the initiation of the adaptive immune response in the dLNs of the vagina in the first few d.p.i. At 2 d.p.i., the cellularity of dLNs from HSV-1-infected mice was considerably greater than that of dLNs from mice that were mock infected or HSV-2 infected (Figure 2A). To understand the difference in LN cellularity between HSV-1- and HSV-2infected mice, we examined the DC compartment within the $\mathrm{dLN}$, as these cells are crucial for both $\mathrm{LN}$ enlargement and T cell activation $(33,34)$. DCs in the $\mathrm{dLN}$ were identified as CD11 $\mathrm{c}^{\text {hi }} \mathrm{MHCII}{ }^{\mathrm{hi}}$, and this population was subdivided by expression of CD103 and CD11b into 3 subsets that distinguish between $\mathrm{CD}_{11 b^{+}} \mathrm{cDC} 2 \mathrm{~s}$ and $\mathrm{CD}_{103}$ (double negative, DN) versus CD103 ${ }^{+} \mathrm{cDC} 1 \mathrm{~s}$ (Figure 2B, Supplemental Figure 3A) (35). After vaginal HSV-1 infection, total DC numbers were elevated in the dLN at 2 d.p.i. (Figure 2C). We also observed a significantly higher number of cells within each of the 3 DC subsets after HSV-1 infection than after mock or HSV-2 infection (Figure 2, D-F). Inoculation of mice with low-passage, primary clinical isolates of HSV-1 and HSV-2 showed similar differences in disease and survival as observed with laboratory strains (Supplemental Figure 4, A and B), and it also yielded increases in total DC numbers and DC subsets in the dLN after HSV-1 infection compared with HSV-2 (Supplemental Figure 5, A-D).

To identify potential differences in DC function after HSV-1 or HSV-2 infection, we examined the maturation status of the DCs in the dLN by measuring cell surface expression of the costimulatory molecule CD86. CD86 expression was highly upregulated on the total DC population after HSV-1 infection compared with both mock and HSV-2 infection (Figure 2G). When assessing individual DC subsets after HSV-1 infection, we observed increased CD86 expression on $\mathrm{CD}_{11 \mathrm{~b}^{+}}$and CD103 ${ }^{+} \mathrm{DCs}$, but not on DN DCs (Figure 2, H-J). Furthermore, although CD11 b $\mathrm{b}^{+}$D numbers were unchanged after HSV-2 infection compared with mock-inoculated animals (Figure 2D), CD86 expression was higher on this subset when compared with mock-infected controls (Figure $2 \mathrm{H}$ ), suggesting that DCs in the dLN of HSV-2-infected mice were not entirely unresponsive. The difference in CD86 expression on DCs from mice infected with HSV-1 and HSV-2 also was maintained when mice were inoculated with clinical isolates (Supplemental Figure 5, E-H). Together, our data show that maturation and accumulation of DCs in the dLN are observed at an early time point after vaginal HSV-1 infection but not after HSV-2 infection.

Rapid IFN- $\gamma$ production after HSV-1 infection is important for accelerated DC maturation. IFNs are a major component of host defense against pathogens and have a strong impact on the development of immune responses. We hypothesized that any differences in IFN production would likely need to occur very early in order to affect DC maturation and numbers in the dLN. Thus, we assessed IFN production in the vagina 1 day after inoculation to determine whether differences in IFN expression were associated with the disparity in DC maturation observed after HSV-1 and HSV-2 infection. When we measured IFN- $\alpha$ and IFN- $\beta$, 2 type I IFNs, we found minimal induction of either cytokine (Figure $3 \mathrm{~A}$ ), in agreement with previous reports $(36,37)$. IFN- $\lambda$, which is a type III IFN whose activity is largely restricted to mucosal surfaces (38), was detected in the vagina 1 day after both HSV-1 and HSV-2 infection (Figure 3B). However, IFN- $\lambda$ levels were similar after HSV-1 and 
A

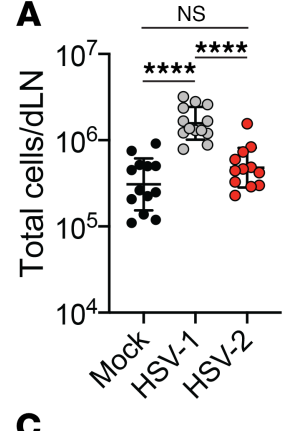

c

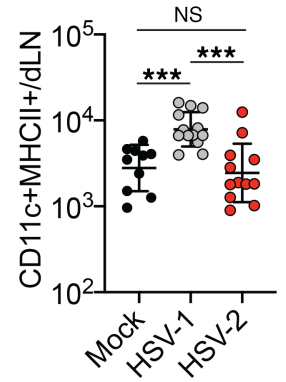

G
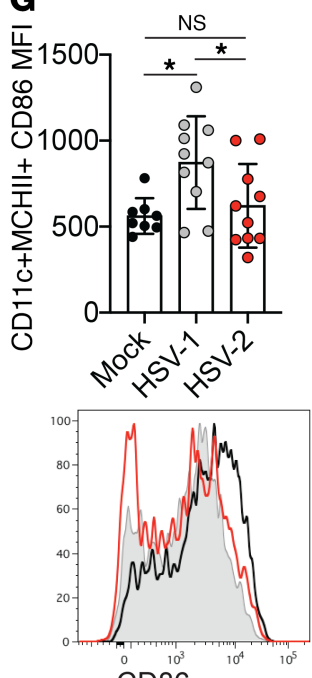

B

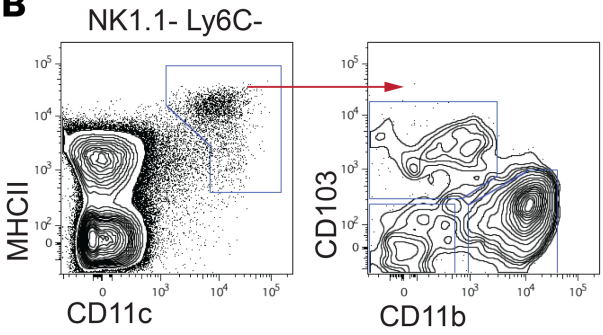

D

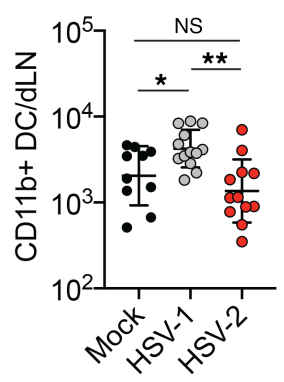

H

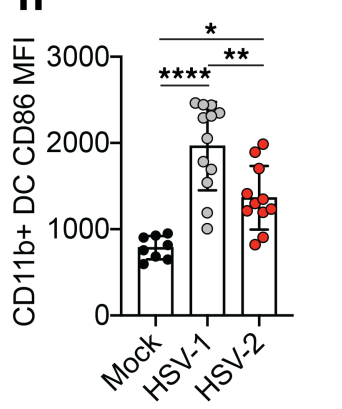

E

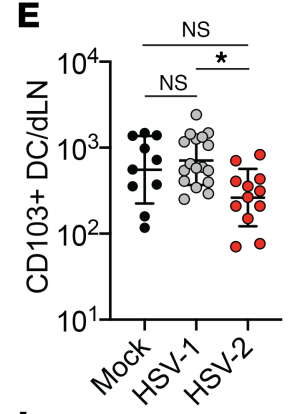

I
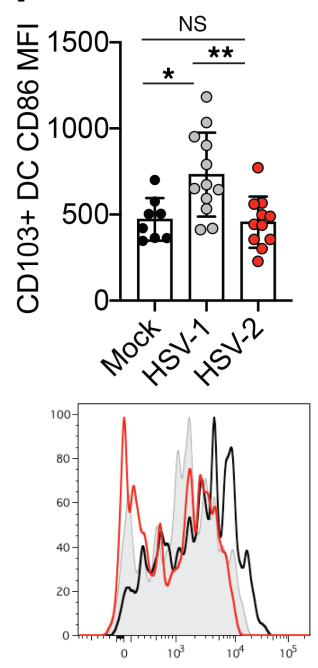

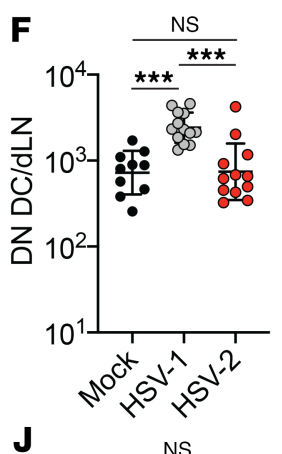

J
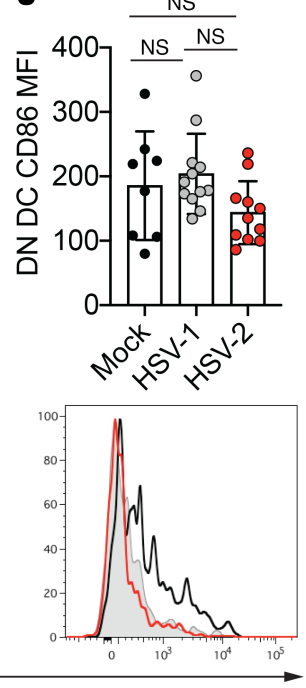

Mock

HSV-1

HSV-2

Figure 2. Greater numbers of mature DCs are present in the draining lymph node after HSV-1 infection than after HSV-2 infection. Eight-week-old [57BL/6) females were injected with Depo-Provera and inoculated intravaginally with $1 \times 10^{4}$ PFU HSV- 1 strain McKrae, HSV- 2 strain 186 syn ${ }^{+}$, or PBS as a control. (A) Total number of live cells in the draining lymph node (dLN) 2 days after infection with HSV-1 ( $n=13)$, HSV-2 $(n=12)$, or mock $(n=13)$ inoculation with PBS. (B) Representative flow plots showing gating strategy for DCs in the dLN. Left plot is gated on live NK1.1-Ly6C- ${ }^{-}$cells. Right plot is gated on

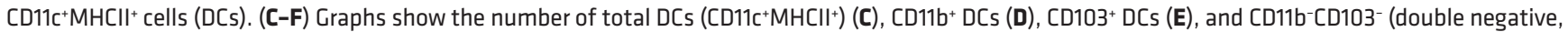
DN) DCs (F) at 2 d.p.i. per dLN (HSV-1, $n=13-17$; HSV-2, $n=12$; mock, $n=10)$. (G-J) Graphs show mean fluorescence intensity (MFI) of CD86 expression on

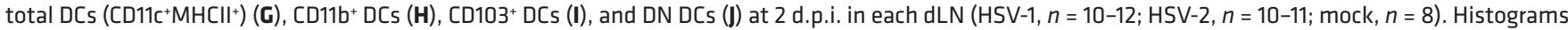
show representative expression of CD86 on each DC subset from mock- (shaded gray), HSV-1- (black), or HSV-2-infected (red) mice; histograms show representative data of the graphs directly above. All data are pooled from 3 independent experiments. Horizontal bars indicate geometric mean; error bars show \pm SD. Statistical significance was measured by 1-way ANOVA with Tukey's multiple comparisons test. ${ }^{*} P<0.05,{ }^{* *} P<0.01,{ }^{* * *} P<0.005$, ${ }^{* * * *} P<0.001$.

HSV-2 infection, indicating that IFN- $\lambda$ was likely not responsible for differences in DC maturation. Indeed, infection of IFN- $\lambda$ receptor-deficient (IFN- $\lambda$ R-deficient) animals with HSV-1 had no impact on the expression of CD86 on DCs within the dLN compared with WT controls (Supplemental Figure 6, A-D). We next evaluated IFN- $\gamma$ secretion in the vagina at day 1 after HSV-1 and HSV-2 infection, and we discovered robust IFN- $\gamma$ production after HSV-1 but not HSV-2 infection (Figure 3C). Similar patterns of IFN- $\gamma$ production were observed after infection with different inoculum doses of HSV-1 and HSV-2 (Figure 3D) and after infection with clinical isolates (Supplemental Figure 7), suggesting that differential IFN- $\gamma$ production at 1 d.p.i. was a distinguishing feature between these 2 infections and independent of infectious viral input. Furthermore, 
A
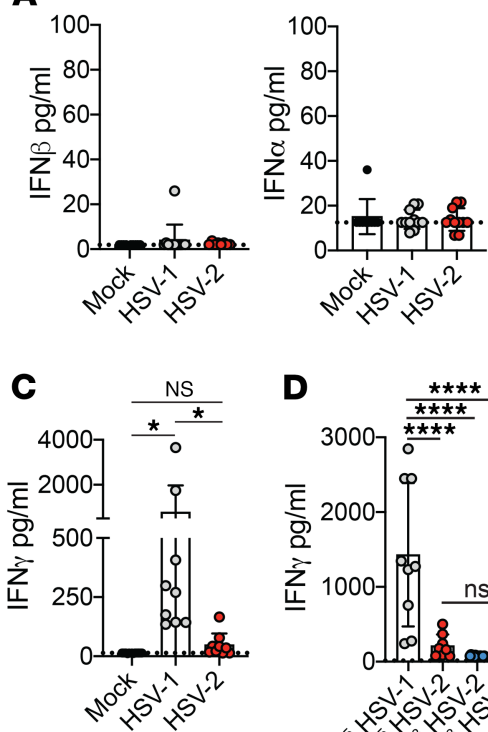

$\mathbf{F}$

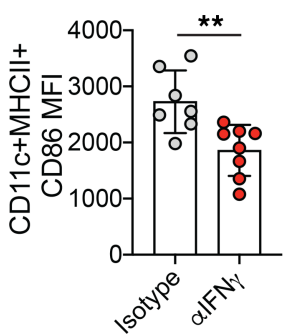

D
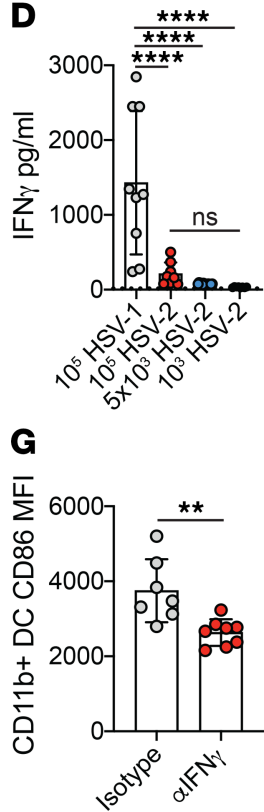
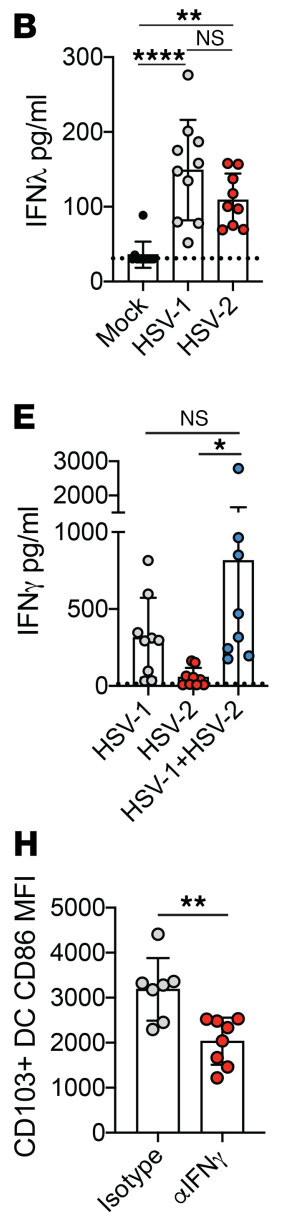

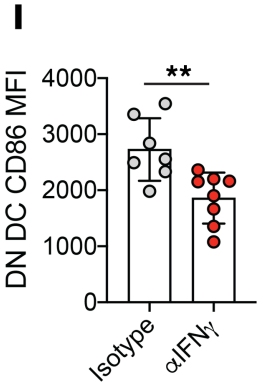

Figure 3. IFN- $\gamma$ production occurs early after HSV-1 but not HSV-2 infection. Infections were performed as described in Figure 2. IFN- $\beta$ (mock, $n=10$; HSV-1, $n=12$; HSV-2, $n=8$ ) and IFN- $\alpha$ (mock, $n=9$; HSV-1, $n=11 ; \mathrm{HSV}-2, n=11)(\mathbf{A})$, IFN- $\lambda$ (mock, $n=11$; HSV-1, $n=10$; HSV-2, $n=10$ ) (B), and IFN- $\gamma$ (mock, $n=15$; HSV-1, $n=9$; HSV-2, $n=9$ ) (C) were measured at 1 d.p.i. from vaginal washes. Dashed lines indicate limit of detection. (D) Mice were inoculated with $1 \times 10^{5} \mathrm{PFU}$ HSV-1 $(n=9), 1 \times 10^{5} \mathrm{HSV}-2(n=8), 5 \times 10^{3}$ PFU HSV-2 $(n=8)$, or $1 \times 10^{3}$ PFU HSV-2 $(n=8)$, and IFN- $\gamma$ was measured at 1 d.p.i. from vaginal washes. (E) Mice were inoculated with $1 \times 10^{4} \mathrm{PFU}$ HSV-1 alone or $1 \times 10^{4} \mathrm{PFU}$ HSV-2 alone, or coinoculated with $1 \times 10^{4}$ PFU HSV- 1 and HSV-2 ( $n=9$ for all groups). IFN- $\gamma$ production was measured at 1 d.p.i from vaginal washes. In F-I, HSV-1-infected mice were treated intravaginally with $100 \mu \mathrm{g} \alpha \mathrm{IFN}-\gamma$ neutralizing antibody $(n=8)$ or isotype

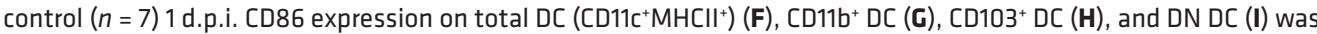
measured 2 d.p.i. All data are pooled from 2 independent experiments. Error bars show \pm SD. Dashed lines in graphs show limit of sensitivity for ELISA assay. Statistical significance was measured by 1-way ANOVA with Tukey's multiple comparisons test (A-E) or 2-tailed Student's $t$ test $(\mathbf{F}-\mathbf{I}) .{ }^{*} P<0.05,{ }^{* *} P<0.01,{ }^{* * *} P<0.001$.

coinoculation with both HSV-1 and HSV-2 led to IFN- $\gamma$ production that closely resembled that of HSV-1 inoculation alone (Figure 3E), indicating that the IFN- $\gamma$ induction by HSV-1 infection was not suppressed by HSV-2 infection at 1 d.p.i. To determine whether neutralization of the early IFN- $\gamma$ response after HSV-1 could alter DC maturation status, we intravaginally treated HSV-1-infected mice with an IFN- $\gamma$-neutralizing antibody or an isotype control. Upon IFN- $\gamma$ neutralization after HSV-1 infection, we found that, at 2 d.p.i., CD86 expression was markedly reduced on total DCs (Figure 3F), as well as on each DC subset (Figure 3, G-I) in the dLN. Thus, our data show that distinct induction of IFN- $\gamma$ in the vagina after HSV-1 and HSV-2 infection is a key factor in determining the maturation status of DCs.

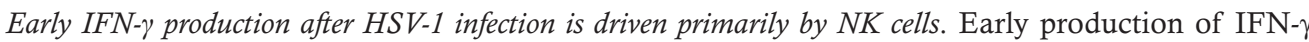
after genital HSV-2 infection in mice has been reported to occur at 2 d.p.i., and our infection model confirms this finding (Supplemental Figure 8) (39-41). The day 2 production of IFN- $\gamma$ after primary HSV-2 infection is largely dependent on NK cells $(39,41)$. To test whether these cells were also important for IFN- $\gamma$ production at day 1 after HSV-1 infection, mice were treated with a depleting antibody against 
A

$a \mathrm{NK} 1.1 \mathrm{Ab}$

or

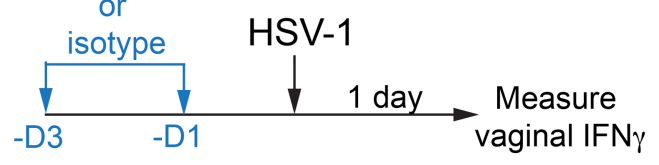

B

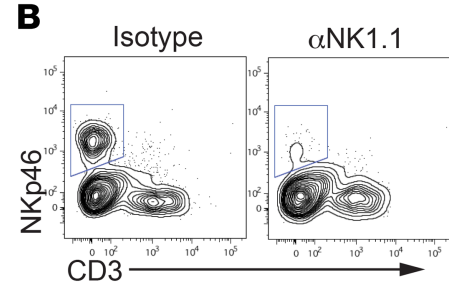

E
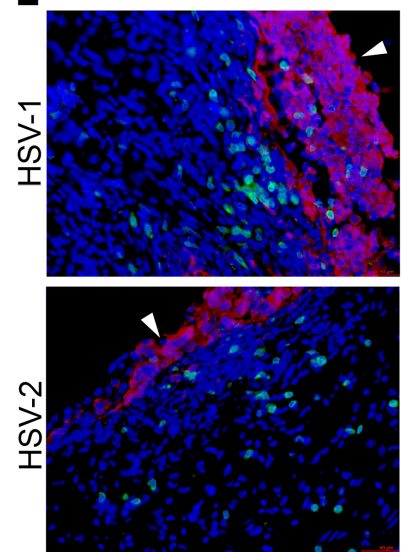

NK cells HSV (AF647) DAPI
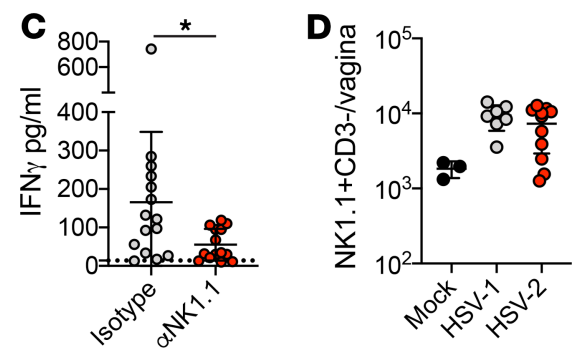

F Infected areas

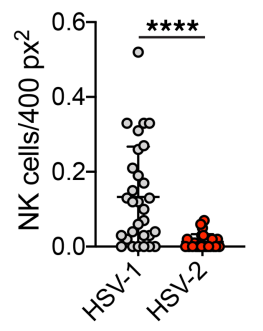

G Proximal areas

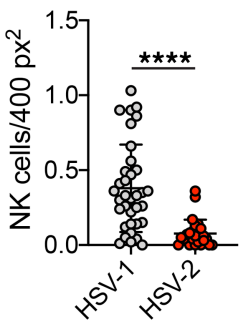

Figure 4. NK cells mediate IFN- $\gamma$ production early after HSV-1 infection. (A) Experimental schematic for NK cell depletion. At 3 and 1 days prior to infection with HSV-1 (performed as describe in Figure 1), mice were injected i.p. with 200 $\mu \mathrm{g} \alpha \mathrm{NK} 1.1$ antibody or an isotype control. (B) Flow plots show NK cell depletion in the vagina 1 day after HSV-1 infection. Flow plots are gated on Ly6G- live cells. (C) IFN- $\gamma$ was measured by ELISA from vaginal washes taken 1 d.p.i. (isotype, $n=15$; $\alpha$ NK1.1, $n=15$ ). (D) NK cell numbers in the vagina 1 d. p.i. (mock, $n=3$; HSV-1, $n=7$; HSV-2, $n=11$ ). (E) Immunofluorescent analysis of vaginal tissue sections from Ncr ${ }^{\mathrm{mT} / \mathrm{mC}}$ reporter mice at 1 day after HSV-1 or HSV-2 infection. NK cells are shown in green, HSV proteins (detected with Alexa Fluor 647) are shown in red, and nuclei are shown in blue. White arrowheads indicate luminal border of the epithelium. NK cell numbers were counted in infected areas (HSV-1, $n$ $=30$; HSV-2, $n=25)(\mathbf{F})$ and in areas proximal to infected areas (within $12 \times 10^{4}$ pixels, approximately $\left.75 \mu \mathrm{m}\right)(\mathrm{HSV}-1, n=$ 35 ; HSV-2, $n=25$ ). (C). At least 2 infected areas were counted from 4 independent sections with 3 mice per group. Data are pooled from 2 (D-G) or 3 (B) independent experiments. Horizontal bars show mean (C, F, G) or geometric mean (D); error bars show \pm SD. Statistical significant was measured by 2-tailed Student's $t$ test (C), 1-way ANOVA with Tukey's multiple comparisons test (D), or Mann-Whitney $U$ test (F and $\mathbf{G}) .{ }^{*} P<0.05,{ }^{* * * *} P<0.001$.

NK cells (Figure 4, A and B). Antibody-mediated depletion of NK cells resulted in a marked decrease in IFN- $\gamma$ production after HSV-1 infection, suggesting a critical role for NK cells in rapid, local cytokine production (Figure 4C). However, we found no substantial differences in NK cell numbers in the vagina when measured at 1 day after HSV-1 or HSV-2 infection, suggesting that accumulation of NK cells in the vagina was similar after inoculation with these 2 viruses (Figure 4D). To determine whether access of NK cells to sites of infected epithelium might distinguish early responses against HSV-1 and HSV-2, we examined the distribution of NK cells in the vagina after HSV-1 or HSV-2 infection of Ncr1-Cre $\times$ ROSA26mTd/mGFP reporter mice ( $\mathrm{Ncr}^{\mathrm{mT} / \mathrm{mG}}$ ) (42) (Figure 4E). Strikingly, there was a marked increase in the number of NK cells recruited to infected epithelial cells (Figure 4F) and areas proximal to the infected epithelium (Figure 4G) after HSV-1 inoculation compared with HSV-2, suggesting that appropriate localization of NK cells within the vagina may be required for immediate IFN- $\gamma$ production after HSV infection. Together, our data identify an important role for NK cells in mediating very early IFN- $\gamma$ responses after HSV-1, which is absent after HSV-2 genital infection. 

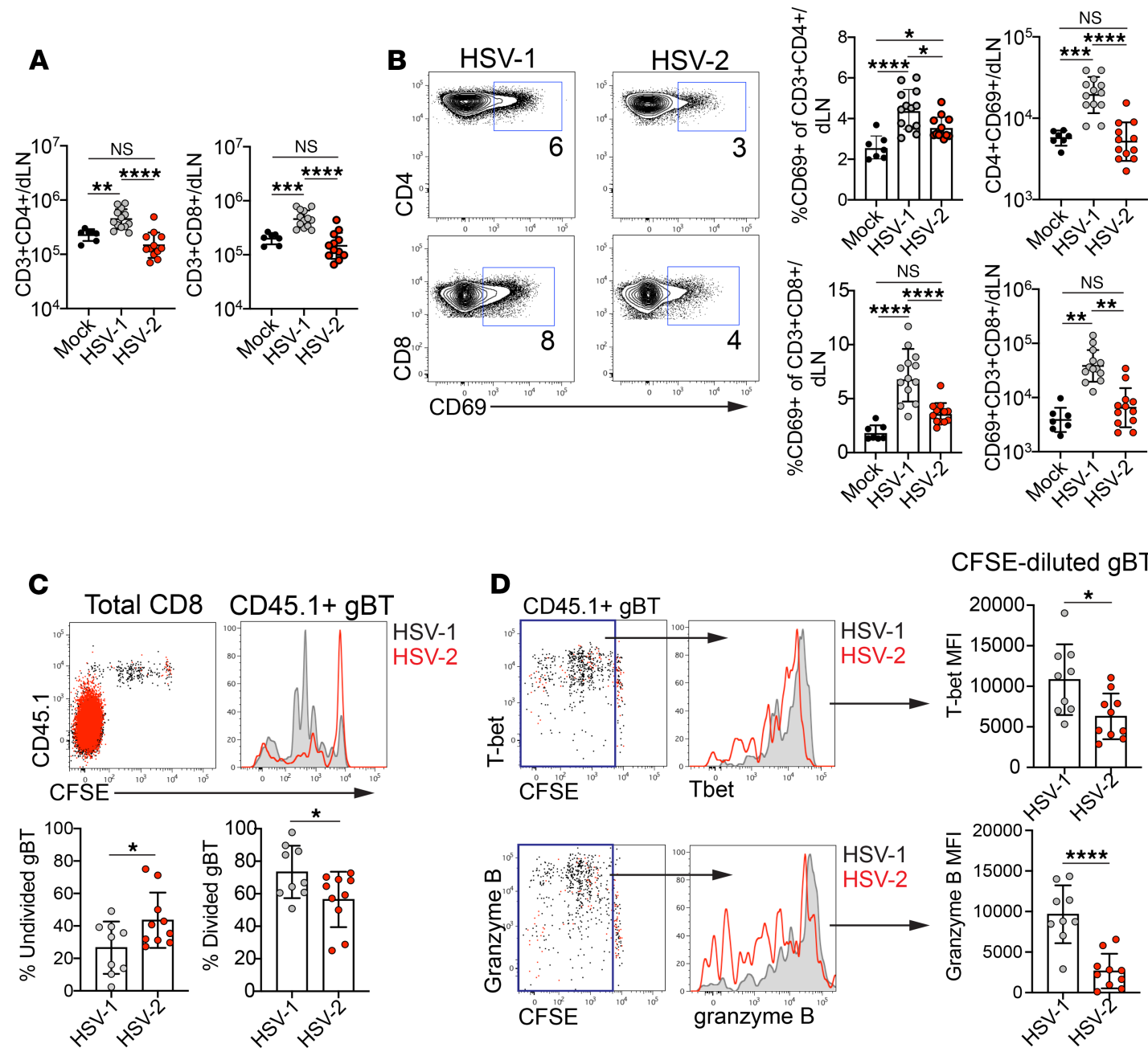

CFSE-diluted gBT-I

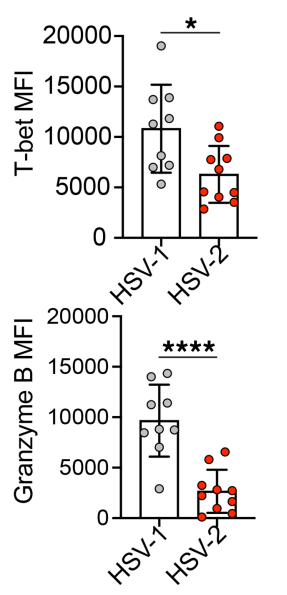

Figure 5. Rapid T cell activation occurs after vaginal HSV-1 infection. Infections were performed as described in Figure 2. (A) Total number of CD4+ T cells (left graph) and CD8+ T cells (right graph) at 2 d.p.i. in the dLN. (B) Plots show expression of CD69 on CD4+ (top) and CD8 (bottom) T cells after HSV-1 (left) or HSV-2 (right) infection. Numbers indicate percentage of CD4+ or CD8 ${ }^{+}$T cells expressing CD69. Left graphs show frequency of CD69 expression in CD4+ (top) or CD8 ${ }^{+}$(bottom) T cells. Right graphs show number of CD69+CD4+ (top) or CD69+CD8+ (bottom) T cells. All data area at 2 d.p.i. in the dLN. (C-D) A total of $1 \times$ $10^{6}$ CFSE-labeled, CD45.1 $1^{+}$gBT-I CD8 ${ }^{+}$T cells were adoptively transferred to congenic naive recipients 1 day before HSV-1 or HSV-2 infection. (C) Plot is gated on total CD8 ${ }^{+} \mathrm{T}$ cells and shows CFSE dilution of gBT-I cells at 3 d.p.i. in the dLN. Histogram shows an overlay of gBT-I cells after HSV-1 (black) or HSV-2 (red) infection. Left graph shows percentage of CFSE-undivided (CFSE-undiluted) gBT-I cells. Right graph shows percentage of CFSE-divided (CFSE-diluted) gBT-I cells. (D) Plots are gated on gBT-I CD8 ${ }^{+}$T cells from the dLN and show expression of T-bet (top) and granzyme B (bottom) 3 days after HSV-1 infection. Boxes are drawn around divided gBT-I cells. Histograms show T-bet and granzyme B expression in divided gBT-I cells after HSV-1 (black) or HSV-2 (red) infection. MFI of T-bet expression (top graph) or granzyme B expression in the divided gBT-I population (bottom graph) is shown. Data in $\mathbf{A}$ and $\mathbf{B}$ are pooled from 3 independent experiments (HSV-1, $n=13$; HSV-2, $n=12$; mock, $n=7$ ). Data in $\mathbf{C}$ and $\mathbf{D}$ are pooled from 2 independent experiments (HSV-1, $n=9$; HSV-2, $n=10$ ). Horizontal bars show mean, and all error bars show \pm SD. Statistical significance in $\mathbf{A}$ and $\mathbf{B}$ was measured by 1-way ANOVA with Tukey's multiple comparisons test. Statistical significance in $\mathbf{A}$ and $\mathbf{B}$ was measured by 2-tailed Student's $t$ test. ${ }^{*} P<0.05,{ }^{* *} P<0.01,{ }^{* * *} P<0.005,{ }^{* * * *} P<0.001$.

Activation and effector differentiation of T cells occurs earlier during HSV-1 infection than HSV-2 infection. To determine whether greater numbers of mature DCs in the dLN after HSV-1 infection enhanced T cell responses, we measured $\mathrm{T}$ cell activation status and effector differentiation in the dLN after HSV-1 and HSV2 infection. Higher numbers of both $\mathrm{CD}^{+}$and $\mathrm{CD} 8^{+} \mathrm{T}$ cells were present in the dLN at 2 days after HSV-1 infection, compared with mock infection or HSV-2 infection (Figure 5A). Furthermore, in HSV-1-infected mice, a greater percentage of both $\mathrm{CD}^{+}$and $\mathrm{CD} 8^{+} \mathrm{T}$ cells expressed $\mathrm{CD} 69$, an early activation marker, compared with T cells from mock-infected or HSV-2-infected mice (Figure 5B). Accordingly, a substantially higher number of $\mathrm{CD} 4^{+} \mathrm{CD} 69^{+}$and $\mathrm{CD} 8{ }^{+} \mathrm{CD} 69^{+} \mathrm{T}$ cells were present in the dLN after HSV-1 than HSV-2 infection (Figure 5B). Infection with low-passage clinical isolates of HSV-1 and HSV-2 also resulted in greater numbers of both $\mathrm{CD}^{+}$and $\mathrm{CD} 8^{+} \mathrm{T}$ cells in the $\mathrm{dLN}$ (Supplemental Figure 9, A and B). The percentage of $\mathrm{CD}^{+} \mathrm{T}$ cells expressing CD69 was similar after infection (Supplemental Figure 9C), whereas the fraction of 
A
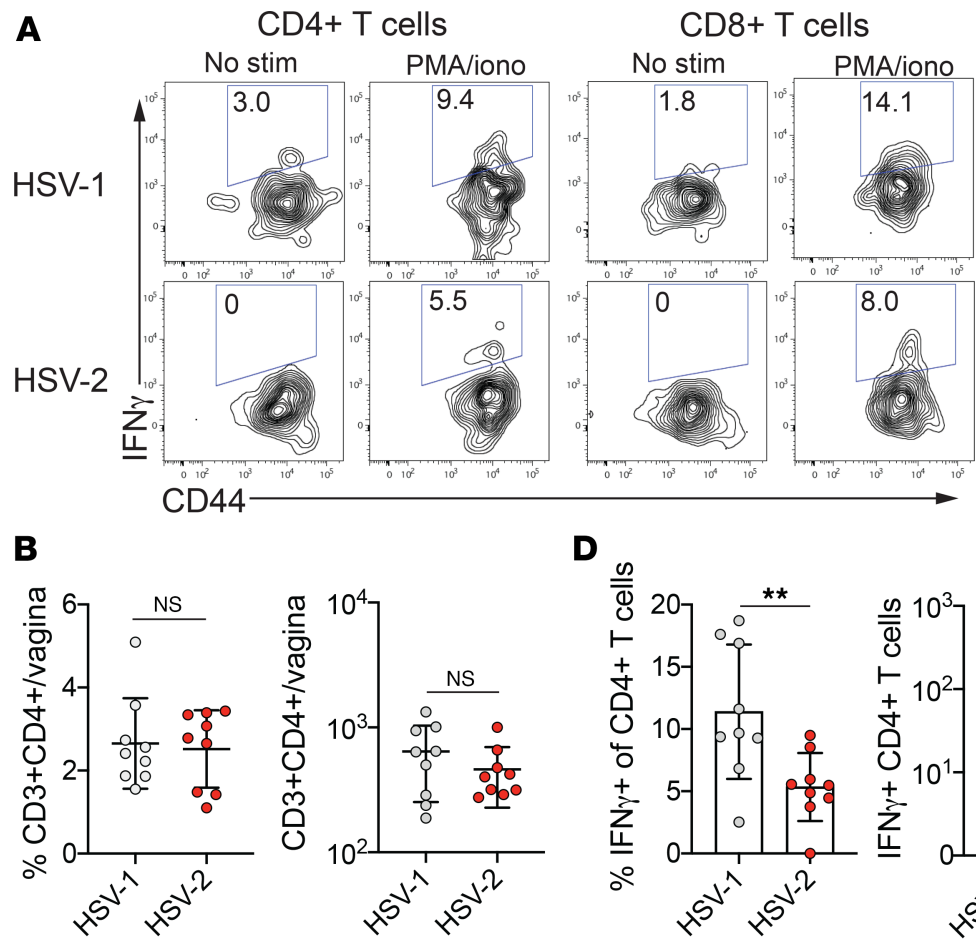

D

C

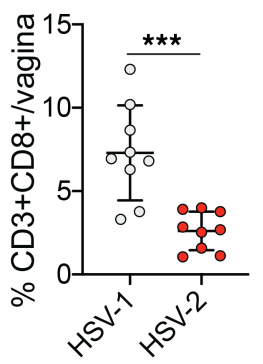

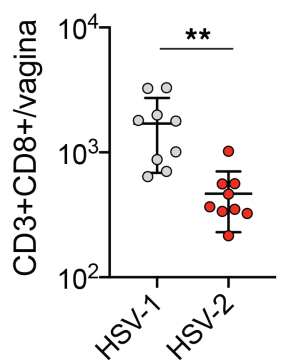

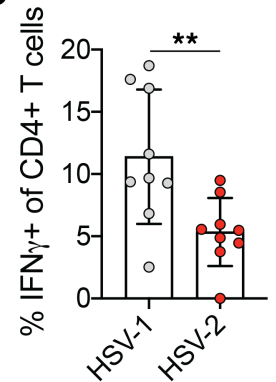

E

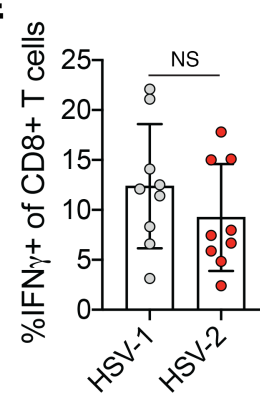

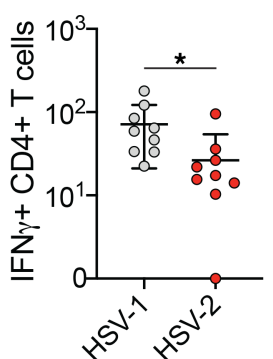

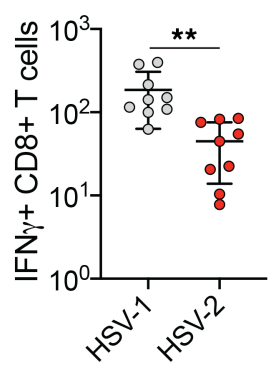

$\mathbf{F}$

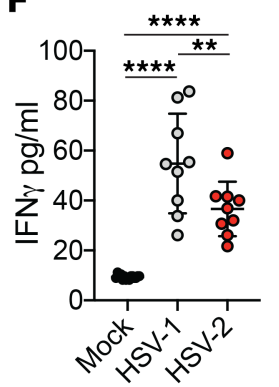

Figure 6. Greater numbers of IFN- $\gamma$-producing $\mathbf{T}$ cells accumulate in the vagina after HSV-1 but not HSV-2 infection. Infections were performed as described in Figure 2. (A) IFN- $\gamma$-producing CD4+ (left) and CD8 $8^{+}$(right) T cells were assessed after HSV-1 (top row) or HSV-2 (bottom row) infection at 4 d.p.i. in the vagina. Plots are gated on live $\mathrm{CD}^{+} \mathrm{CD} 4^{+}$cells (left) or live $\mathrm{CD} 3^{+} \mathrm{CD} 8^{+}$cells (right) after excluding NK cells and neutrophils. Number in plots shows frequency of IFN- $\gamma^{+}$cells in the $\mathrm{CD} 4^{+}$or $\mathrm{CD} 8^{+} \mathrm{T}$ cell populations. Frequency and total number of CD4 ${ }^{+} \mathrm{T}$ cells (B), as well as frequency (left) and number (right) of IFN- $\gamma^{+}$CD4 ${ }^{+} T$ cells (D) in the vagina at 4 d.p.i. are shown. Frequency and total number of CD8 $8^{+}$cells (C), as well as frequency (left) and number (right) of IFN- $\gamma^{+} \mathrm{CD}^{+} \mathrm{T}$ cells (E) in the vagina at 4 d.p.i. are shown. (F) IFN- $\gamma$ was measured by ELISA assay in vaginal washes collected from virus- or mock-infected mice at day 4. Data are pooled from 2 independent experiments (HSV-1, $n=9 ;$ HSV-2, $n=9$ ). Horizontal bars show mean; all error bars show $\pm \mathrm{SD}$. Statistical significance in B-E was measured by 2-tailed Student's $t$ test. Statistical significance in $\mathbf{F}$ was measured by 1 -way ANOVA with Tukey's multiple comparisons test. ${ }^{*} P<0.05,{ }^{* *} P<0.01,{ }^{* * *} P<0.005,{ }^{* * *} P<0.001$.

$\mathrm{CD} 8^{+} \mathrm{T}$ cells expressing CD69 was higher after infection with HSV-1 compared with HSV-2 (Supplemental Figure 9D). Regardless of the frequency of CD69 expression, the total number of both $\mathrm{CD} 4^{+}$(Supplemental Figure 9E) and $\mathrm{CD}^{+}$(Supplemental Figure 9F) T cells was higher after HSV-1 compared with HSV-2.

To determine whether increased CD69 expression at 2 d.p.i. resulted in more rapid onset of the effector $\mathrm{T}$ cell response, we examined proliferation of virus-specific $\mathrm{T}$ cells using $\mathrm{T}$ cell receptor (TCR) transgenic $\mathrm{CD}^{+} \mathrm{T}$ cells that recognize an epitope derived from glycoprotein B of HSV (gBT-I) (43). Congenically marked CD45.1 ${ }^{+}$gBT-I cells were labeled with CFSE and adoptively transferred to female recipients. Recipients were inoculated intravaginally with HSV-1 or HSV-2, and dilution of CFSE was measured in the dLN at 3 d.p.i. (Figure 5C). Whereas the majority of CFSE-labeled gBT-I cells had undergone at least 1 cell division in HSV-1-infected mice, a high proportion of CFSE-labeled gBT-I cells remained undivided in HSV-2-infected mice at this time point (Figure 5C). When divided cells were evaluated for upregulation of the transcription factor T-bet and the cytolytic granule granzyme B to assess effector differentiation, we found that the expression levels of both molecules were higher in gBT-I cells responding to an HSV-1 than 
A

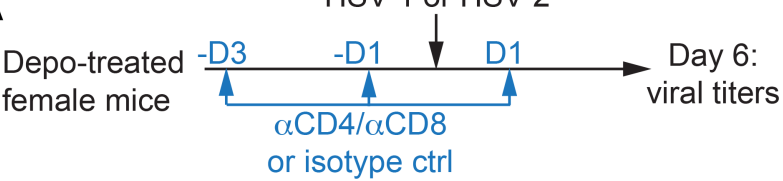

B
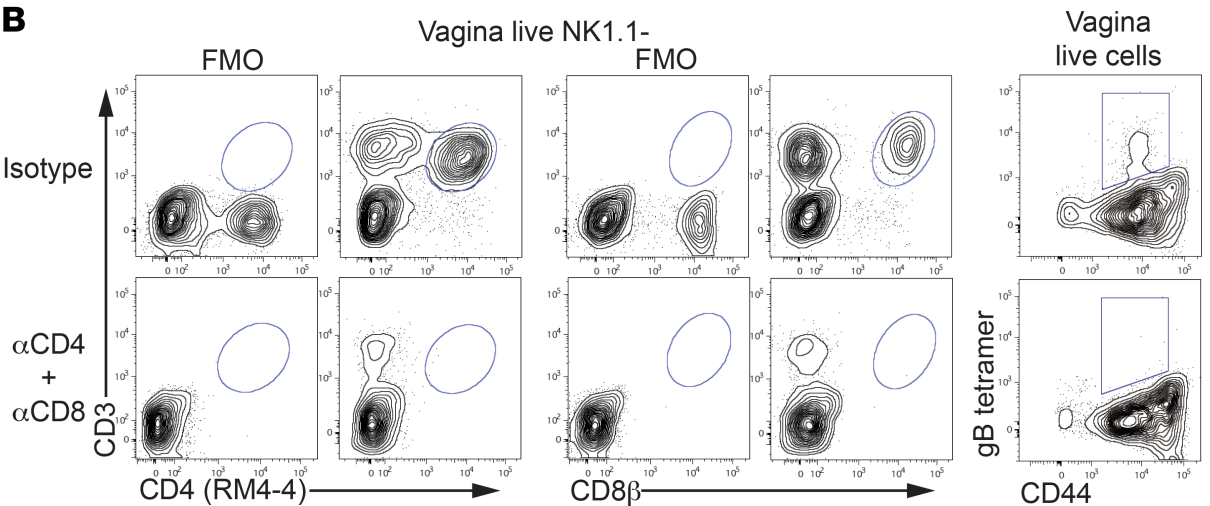

C

$$
\text { Day } 2
$$

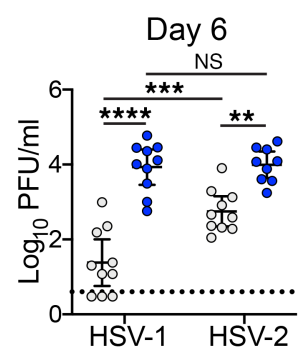

D Day 6
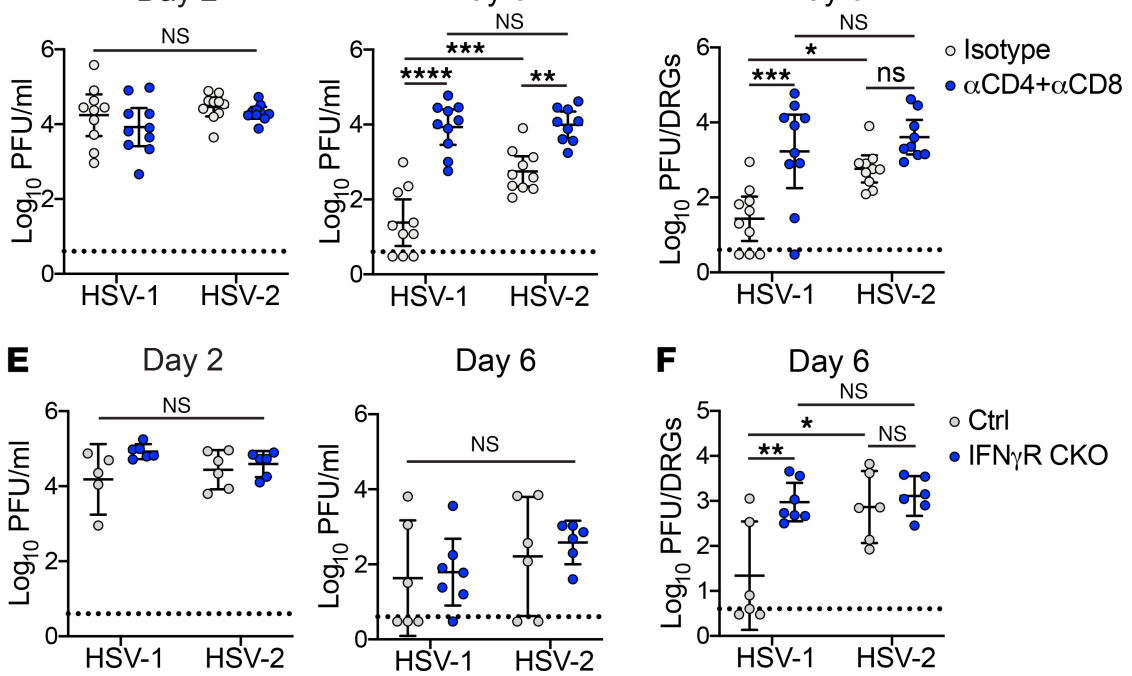

Figure 7. T cells and IFN- $\gamma$ are critical for reducing neuronal viral burden after HSV-1 but not HSV-2 infection. (A) Eight-week-old [57BL/6] female mice were treated with Depo-Provera. Mice were injected i.p. with a combination of $\mathrm{CD}^{+}$and $\mathrm{CD} 8^{+} \mathrm{T}$ cell-depleting antibodies or with an isotype control at 1 and 3 days prior to and 1 d.p.i. (B) Representative plots show efficiency of T cell depletion at 6 d.p.i. in vagina. Top row shows isotype control; bottom shows mice treated with depleting antibodies. Left columns of plots are gated on live, NK1.1- cells and show CD4+ (left 2) and $\mathrm{CD}^{+}$(middle 2) T cells with corresponding FMO controls. Right column of plots are gated on total live cells from the vagina and show the presence or absence of HSV-specific T cells. (C) Replicating virus was measured by plaque assay in vaginal washes collected on 2 (left graph) or 6 (right graph) d.p.i. from T cell-depleted $(n=9)$ or isotypetreated controls $(n=10)$. (D) Replicating virus was measured by plaque assay in the lumbar-sacral DRG at 6 d.p.i. from T cell-depleted or isotype-treated controls. (E) Replicating virus was measured by plaque assay at 2 (left graph) and 6 (right graph) d.p.i. in vaginal washes from IFN- $\gamma$ R CKO $(n=6-7)$ or littermate controls $(n=5-6)$. (F) Replicating virus was measured by plaque assay at 6 d.p.i. in lumbar-sacral ganglia IFN- $\gamma$ R CKO or littermate controls. Data are pooled from 3 (A-D) or 2 (E-F) independent experiments. Horizontal lines show mean; vertical bars show 95\% Cl. Statistical significance was measured by 2-way ANOVA with Bonferroni multiple comparisons test on log-transformed data. ${ }^{*} P<$ $0.05,{ }^{* *} P<0.01,{ }^{* *} P<0.005,{ }^{* * *} P<0.001$.

HSV-2 infection (Figure 5D). Thus, T cells are activated and acquire features of effector T cells more rapidly after vaginal HSV-1 than HSV-2 infection.

$H S V-1$ infection leads to greater IFN- $\gamma$ production and more rapid accumulation of IFN- $\gamma$-producing $T$ cells at sites of infection than HSV-2. We next tested whether the rapid T cell activation after HSV-1 infection resulted in earlier accumulation of effector $\mathrm{T}$ cells at the primary site of infection. IFN- $\gamma$ is crucial for controlling 
against HSV infection in multiple tissues, including neurons (21, 24, 44, 45), and - after the first few days of infection - is predominantly produced by $\mathrm{T}$ cells (40). We hypothesized that $\mathrm{T}$ cells would need to act rapidly after HSV-1 infection to confer neuroprotection. As $\mathrm{T}$ cells had already begun to differentiate into effector T cells within the dLN at 3 d.p.i., we assessed the influx of IFN- $\gamma$-producing cells into the vagina 4 days after HSV-1 or HSV-2 infection. Due to the difficulty in evaluating virus-specific T cells so early in the primary response, we stimulated vaginal $\mathrm{T}$ cells with PMA and ionomycin to assess their capacity for IFN- $\gamma$ production (Figure $6 \mathrm{~A}$ ). Although total vaginal $\mathrm{CD}^{+} \mathrm{T}$ cell numbers were not different after HSV-1 and HSV-2 infection (Figure 6B and Supplemental Figure 3B), a higher frequency and number of CD4 ${ }^{+}$ T cells produced IFN- $\gamma$ after HSV-1 infection (Figure 6, A and D). In contrast, whereas the proportion of $\mathrm{CD}^{+} \mathrm{T}$ cells that produced IFN- $\gamma$ was similar between the $2 \mathrm{HSV}$ infections (Figure 6, A and E), the total number of $\mathrm{CD}^{+} \mathrm{T}$ cells and the number of IFN- $\gamma$-producing CD8 ${ }^{+} \mathrm{T}$ cells was greater after HSV-1 than after HSV-2 infection (Figure 6, C and E, and Supplemental Figure 3B). To determine whether the greater number of IFN- $\gamma$-producing T cells resulted in higher levels of IFN- $\gamma$ secretion in the vagina after HSV-1 infection compared with HSV-2 infection, we measured cytokine levels in the lumen and found increased IFN- $\gamma$ secretion in the vagina after HSV-1 infection compared with HSV-2 infection (Figure 6F). Thus, we find that accelerated $\mathrm{T}$ cell activation after HSV-1 infection results in greater accumulation of T cells competent for IFN- $\gamma$ production and the potential for robust early cytokine secretion at sites of viral replication.

The primary $T$ cell response and neuronal responses to IFN- $\gamma$ are required for neuroprotection against HSV-1 but not $H S V-2$ infection. We next tested whether the rapid T cell response elicited after HSV-1 infection contributed to control of viral infection within the ganglia. Mice were injected i.p. with depleting antibodies against $\mathrm{CD}^{+}$and $\mathrm{CD}^{+} \mathrm{T}$ cells and then inoculated intravaginally with HSV-1 or HSV-2 (Figure 7A). At 6 d.p.i., we measured the efficacy of $\mathrm{T}$ cell depletion (Figure 7B) and viral replication in the ganglia (Figure 7D). Mucosal titers were monitored throughout infection (Figure 7C). While shedding of HSV-1 and HSV-2 into the vaginal lumen was similar regardless of the presence or absence of $\mathrm{T}$ cells at 2 d.p.i., a time point that is expected to be unaffected by the T cell response, there was a clear increase in mucosal titers of both HSV-1 and HSV-2 at 6 d.p.i. (Figure 7C). When viral replication was measured in the ganglia, there was a substantial increase in the amount of replicating HSV-1 within the ganglia compared with T cell-sufficient controls, in the absence of T cells (Figure 7D). In contrast, the impact of T cell depletion on HSV-2 replication within the ganglia was markedly smaller (Figure 7D), despite the increase in mucosal titers (Figure 7C). Thus, our data demonstrate that HSV-1 induces a potent, rapid T cell response that inhibits viral replication in the ganglia, in contrast to HSV-2 infection in which T cell control of viral replication in the ganglia is less effective.

We next investigated the mechanism by which the primary $\mathrm{T}$ cell response confers protection against HSV-1 infection of the ganglia. To determine whether IFN- $\gamma$ was important for suppressing HSV-1 replication in the ganglia, we generated mice in which IFN- $\gamma \mathrm{R}$ expression was abrogated specifically in peripheral neurons by breeding IFN- $\gamma \mathrm{R}^{\mathrm{fl} / \mathrm{fl}} \times$ Advillin-Cre mice (IFN- $\gamma \mathrm{R}$ CKO) (46-48). IFN- $\gamma \mathrm{R}$ CKO mice or Cre-negative littermate controls were inoculated intravaginally with HSV-1 or HSV-2. Mucosal viral shedding was monitored throughout infection (Figure 7E), and at 6 d.p.i., we measured viral titers in the ganglia (Figure7F). Viral shedding into the vaginal mucosa was equivalent between all groups at 2 d.p.i., as expected (Figure 7E). Notably, we observed only minor differences in mucosal HSV-1 and HSV-2 shedding between IFN- $\gamma$ R CKO mice and littermate controls at 6 d.p.i. (Figure 7E), which correlated with similar IFN- $\gamma$ R expression in the vagina between these 2 cohorts (Supplemental Figure 10). Despite this, the amount of viral replication in the ganglia was significantly higher in HSV-1-infected IFN- $\gamma \mathrm{R}$ CKO mice when compared with littermate controls, whereas ganglia titers of HSV-2-infected IFN- $\gamma \mathrm{R}$ CKO and littermate controls were similarly high (Figure 7F), suggesting that increased levels of replicating HSV-1 in the ganglia occur independently of effects on mucosal replication. Thus, neuronal IFN- $\gamma-$ mediated antiviral responses can limit HSV-1 viral replication in the ganglia but fail to control HSV-2.

\section{Discussion}

In this study, we report differences in the kinetics of the T cell response between HSV-1 and HSV-2 vaginal infection, and we reveal an unexpected $\mathrm{T}$ cell-dependent mechanism for regulating neuronal replication after HSV-1 but not HSV-2 infection. We found that both $\mathrm{CD} 4^{+}$and $\mathrm{CD} 8^{+} \mathrm{T}$ cells display robust, early activation after HSV-1 infection, which led to more extensive proliferation of virus-specific $\mathrm{CD} 8^{+} \mathrm{T}$ cells early during the course of HSV-1 infection and faster acquisition of effector T cell features. Our data show that disparities in the kinetics of $\mathrm{T}$ cell activation correlate with increased accumulation of mature DCs 
within the dLN after HSV-1 infection, which in turn was dependent on rapid, NK cell-dependent IFN- $\gamma$ production very early after HSV-1 but not HSV-2 inoculation. The accelerated T cell response after HSV-1 infection was important for suppressing viral replication in the ganglia and was specific to HSV-1, as T cell depletion had only a minor impact on HSV-2 viral replication in the nervous system. Control of HSV-1 ganglionic infection was also dependent on neuronal responsiveness to IFN- $\gamma$, and our evidence implies that the IFN- $\gamma$ required for neuroprotection was provided by $\mathrm{T}$ cells. Together, our data suggest a model in which a rapid T cell response elicited after HSV-1 infection drives a protective IFN- $\gamma$-mediated antiviral program in the peripheral nervous system, likely before viral invasion occurs or becomes too severe, while primary $\mathrm{T}$ cell responses occur too slowly after HSV-2 infection to subdue neuronal infection.

While HSV-1 and HSV-2 are closely related and display similar pathogenesis and cellular tropism, the early host-pathogen interactions that drive differences in disease are incompletely understood. While it is likely that multiple host-pathogen interactions influence the aggressive reactivation patterns of HSV-2, our study suggests that T cell-dependent regulation of HSV replication in the neurons during primary infection may contribute to differences in disease outcome between HSV-1 and HSV-2 by determining the extent of viral replication in the ganglia and, ultimately, the size of the latent reservoir. Studies using attenuated strains of HSV or antiviral intervention have demonstrated a direct relationship between viral replication spread through the ganglia and the number of latently infected neurons, which in turn correlates with in vivo reactivation $(13,49)$. Both HSV-1 and HSV-2 contain variations in genomic sequence, both between laboratory strains $(50,51)$ and clinical isolates $(52-54)$. A recent study interrogating sequence variations in HSV-2 isolated from infected neonates showed a correlation between disease presentation and genomic diversity in viral proteins associated with neurovirulence in animal models, suggesting that these variations have a strong impact on pathogenesis and interaction with host cells (54). The specific virus-host interactions that promote differences in the initiation of the adaptive immune response after HSV-1 and HSV-2 are currently unknown. It will be important to understand whether genetic diversity among HSV strains results in the expression of viral proteins that differentially modulate host immune responses, thus leading to disparate disease outcomes. While the 2 strains of HSV-1 and 2 strains of HSV-2 that we used had similar host response phenotypes, and previous studies using HSV-1 strain KO have also reported comparable findings (55), we acknowledge that our conclusions will need to be corroborated with a broader panel of laboratory strains or clinical isolates of HSV-1 and HSV-2.

Delays in the inflammatory response of the genital tract after vaginal inoculation with HSV-2 (37), as well other RNA viruses (36), have been reported, suggesting that there is a general lag in the antiviral response at the vaginal mucosal surface or that many viruses can successfully suppress antiviral responses in this tissue. Furthermore, after vaginal exposure to RNA viruses, DC maturation and subsequent cytotoxic T cell responses are slow compared with those elicited after i.p. inoculation (36), with activation kinetics similar to our own observations for HSV-2. Although we did not detect any IFN- $\alpha$ or IFN- $\beta$ and relatively low levels of IFN- $\lambda$ after either HSV-1 or HSV-2 infection, IFN- $\gamma$ was robustly produced from an unknown source only after HSV-1 infection. Thus, it appears that HSV-1, unlike HSV-2 or other tested viruses, is unable to suppress or evade a type II IFN response at the vagina. IFN- $\gamma$ production occurs in 2 waves after HSV-2 infection $(39,40)$. The first wave of IFN- $\gamma$, which occurs at 2 d.p.i., is largely driven by NK cells $(39,41)$. Our data demonstrate that early IFN- $\gamma$ production after HSV-1 infection is also dependent on NK cells or ILC1s, a related innate lymphocyte, either through direct cytokine secretion or induction from other another cell type. Whether HSV-1 is directly stimulating NK cells through a pattern recognition receptor (56) or through induction of other proinflammatory cytokines (57) is unknown. However, an important feature that distinguishes HSV-1 from HSV-2 infection appears to be the localization of NK cells to areas of infected vaginal epithelium, which suggests differences in NK cell homing within the vagina. The chemokine CXCL10, a ligand for CXCR3, has been reported to be induced within 24 hours after genital HSV infection, prior to type I IFN production (37). Thus, we hypothesize that differential induction of CXCL10 very early after HSV-1 or HSV-2 by infected epithelial cells or other resident cell types, including stimulated DCs (58), may drive differences in NK cell localization and, ultimately, IFN- $\gamma$ production. CXCL10 expression was linked to O-glycosylation of the virion surface (37), which implies a potential role for glycosylated viral surface proteins in determining the kinetics of the innate host response after HSV-1 or HSV-2 infection.

The activation of DCs, acquisition of viral antigens, and migration into the dLN are crucial for initiating antiviral $\mathrm{T}$ cell responses, and our data indicate that these events are differentially regulated after HSV-1 and HSV-2 infection in an IFN- $\gamma$-dependent manner. It unclear whether IFN- $\gamma$ is acting directly on DCs to induce 
maturation (59) or inducing the production of DC maturation factors by stimulating other cell types such as macrophages. While rapid IFN- $\gamma$ induction appears to be a key difference between HSV-1 and HSV-2 infection, there may be other pathways that lead to disparate rates of DC maturation. One possibility is that the activity of DCs is impaired by direct infection after HSV-2 inoculation, as there is evidence to suggest that HSV can infect DCs and other antigen-presenting cells in vitro (60-62). However, there is currently little in vivo data showing HSV infection of DCs. Careful measurement of viral DNA by PCR in dLNs during the first few days of infection with an attenuated strain of HSV-2 detected little to no DNA within the whole dLN nor within DC populations isolated from the $\operatorname{dLN}(63,64)$, suggesting that DCs relevant for T cell stimulation are not directly infected. However, it is possible that any directly infected DCs may undergo cell death prior to migration and may provide a source of viral antigens for other DCs that carry these antigens to the dLN. HSV does not appear to drain directly into the LN (64-66); thus, it seems unlikely that infection of leukocytes drives the differences in migration and maturation status of DCs after HSV-1 or HSV-2 infection. Instead, our data suggest that distinct inflammatory microenvironments in the vagina lead to slower DC maturation after HSV-2 infection.

The tissue-specific tropism of HSV-1 and HSV-2 raises questions as to whether the differences in immune responses we observe after vaginal infection also occur after other routes of inoculation. HSV-1 infection can cause recurrent disease and significant pathology when introduced into the host through the skin, oral mucocutaneous, or corneal tissues. It is unclear whether similar host-pathogen interactions as we have observed in the vagina are also occurring at these susceptible sites of infection. Further study will be required to determine whether HSV-1 elicits a similarly rapid response after other routes of infection and whether T cells are equally capable of mediating neuroprotection against HSV-1 at peripheral nervous system sites other than the sacral and lumbar DRG.

Interest in understanding the requirements for neuroprotection against HSV is considerable due to the implications for both prophylactic and therapeutic vaccine design. Numerous studies have emphasized the importance of memory $\mathrm{CD}^{+} \mathrm{T}$ cells in controlling HSV infection of the ganglia against a vaginal challenge (26), as well as during reactivation $(14,27)$. Other studies have also revealed a role for memory $\mathrm{CD}^{+} \mathrm{T}$ cells via an antibody-dependent mechanism in protecting the ganglia from infection (25). While memory $\mathrm{T}$ cells are demonstrably important in the context of HSV vaccine design (67) and in restricting mucosal viral replication during recurrent disease $(19,68)$, the role of the primary $\mathrm{T}$ cell response in controlling neuronal infection is less understood. Our data show that primary $\mathrm{T}$ cell responses are required for mucosal control of both HSV-1 and HSV-2 infection but are only effective at suppressing HSV-1 replication in the ganglia. It is unclear why HSV-2 infection of the ganglia is resistant to T cell-mediated control. One possibility is that the mechanisms for T cell-dependent HSV control in the nervous system and in the mucosa are different, and indeed, previous studies have highlighted the importance of cellular pathways such as autophagy in subduing HSV infection specifically within the neuronal compartment (69). HSV encodes numerous viral proteins that suppress or evade host antiviral mechanisms (70), particularly in the nervous system $(69,71,72)$. Thus, there may be a window within which to activate these antiviral pathways within the ganglia to provide efficient control of infection, before the production of these viral proteins. Indeed, at higher vaginal inoculation doses, HSV-1 leads to toxic megacolon through a neuronal route of spread to the gut, suggesting that introduction of a large bolus of virus can lead to immediate dissemination into the peripheral nervous system, thus overcoming T cell-mediated protection (73). The specific mechanisms that lead to neuroprotection against HSV-1 are currently unknown, and further studies will be required to distinguish between the antiviral contributions of $\mathrm{CD}^{+}$and $\mathrm{CD} 8{ }^{+} \mathrm{T}$ cells. As our depletion strategy may have also depleted other CD4- and CD8-expressing cells such as DCs, it possible that these populations may also independently affect neuroprotection against HSV. The importance of neuronal STAT1 signaling in conferring protection against HSV-1 corneal infection has previously been demonstrated (74), and our study suggests that IFN- $\gamma$ signaling may be an important contributor to the induction of STAT1-mediated antiviral pathways. Based on our findings, we hypothesize that T cell responses after HSV-1 infection are fast enough to induce IFN- $\gamma$-dependent antiviral mechanisms in the ganglia (75) that ultimately lead to rapid control of infection, whereas the T cell responses after HSV-2 infection fall outside the requisite window. Although we measure IFN- $\gamma$ levels only in the vagina, it is possible that there is also rapid $\mathrm{T}$ cell-mediated IFN- $\gamma$ production in the ganglia, and further studies will be required to determine whether cytokine secretion at both sites is required to confer robust neuroprotection. Altogether, our study reveals a critical role for T cells in determining the extent of neuronal viral replication after HSV-1 and HSV-2, and it implicates the primary adaptive immune response as an unexpected factor that could regulate the size of the latent reservoir and, thus, the frequency of recurrent disease during genital herpes. 


\section{Methods}

Animals. Six-week-old C57BL/6J mice were purchased from the Jackson Laboratory, rested for at least 1 week, and infected at a minimum of 8 weeks of age. Ifngr $1^{f / f l}$ mice (48), provided by R.D. Schreiber (Washington University), were bred to Advillin-Cre mice (the Jackson Laboratory) (47) to generate Ifngr $1^{f l / f} \times$ Advillin-Cre females and Cre-negative female littermate controls. Litters were screened by PCR. gBT-I TCR transgenic mice specific for the glycoprotein B epitope gB (protein peptide 498-505) (43) were provided by F.R. Carbone (University of Melbourne, Melbourne, Australia) and W.R. Heath (University of Melbourne) and bred to B6.SJL-Ptprc $P e p c^{b} /$ BoyJ mice (the Jackson Laboratory). Rosa ${ }^{\mathrm{mT} / \mathrm{mG}}$ mice were provided by W. Yokoyama (Washington University) (42). IFN- $\lambda$ R-deficient mice were provided by M.T. Baldridge (Washington University) and previously described (76); briefly, these mice were established by interbreeding Ifnlr I ${ }^{\text {tmla(EUCOMM)Wsi }}$ mice and Deleter-Cre mice, followed by backcrossing by speed congenics onto a C57BL/6J background.

Viruses. HSV-1 McKrae (77), HSV-1 ATCC-2011-9 (ATCC VR-1789), HSV-2 186 syn $^{+}$(78), and HSV2 ATCC-2011-4 (ATCC VR-1781) were all propagated and titered in Vero cells (African green monkey kidney epithelial cells, ATCC) as previously described (26). All tissue culture experiments were performed under BSL2 containment.

Animal infection studies. All mice were injected s.c. in the neck once with $2 \mathrm{mg}$ of DMPA (Depo-Provera, Pfizer) 5-7 days prior to primary virus inoculation. For experiments in which T cells were depleted, mice were i.p. injected with $200 \mu \mathrm{g}$ each of $\alpha \mathrm{CD} 4$ (clone GK1.5, Leinco Technologies) and $\alpha \mathrm{CD} 8$ (clone YTS169.4, Leinco Technologies) at 1 and 3 days prior to infection and 1 d.p.i. Controls were treated with 400 $\mu \mathrm{g}$ of rat IgG2b isotype antibody (Leinco Technologies) on the same schedule. For experiments in which NK cells were depleted, mice were i.p. injected with $200 \mu \mathrm{g}$ of $\alpha$ NK1.1 (clone PK136, Leinco Technologies) at 1 and 3 days prior to infection. Controls were treated with $200 \mu$ g of mouse IgG2a isotype antibody (Leinco Technologies) on the same schedule. Five to 7 days after DMPA injection, mice were intravaginally inoculated with $10 \mu \mathrm{L}$ of volume of $1 \times 10^{4} \mathrm{PFU}$ of virus. A sterile calginate swab moistened with sterile PBS was used to gently remove mucous from the vaginal cavity. A pipette tip was inserted into the vagina to deliver the $10 \mu \mathrm{L}$ viral inoculum. Mock-infected animals were inoculated with sterile PBS (vehicle). IFN- $\gamma$ was neutralized after HSV-1 infection by intravaginal inoculation with $100 \mu \mathrm{g} \alpha \mathrm{IFN}-\gamma$ antibody (clone R4-6A2, BioXCell) or with a rat IgG1 isotype control (clone HPRN, BioXCell) 1 d.p.i.

For adoptive transfer of CFSE-labeled gBT-I CD8 ${ }^{+} \mathrm{T}$ cells, $\mathrm{CD} 8^{+} \mathrm{T}$ cells were isolated from spleens of CD45.1 ${ }^{+}$gBT-I TCR Tg mice by magnetic bead sorting (Stem Cell Technologies). CD8 ${ }^{+} \mathrm{T}$ cells were then labeled with CFSE (Invitrogen) at $1 \times 10^{7} \mathrm{cells} / \mathrm{mL}$ at $37^{\circ} \mathrm{C}$ for 10 minutes. A total of $1 \times 10^{6}$ CFSE-labeled gBT-I CD8 ${ }^{+} \mathrm{T}$ cells was adoptively transferred by retro-orbital injection into recipient mice 1 day prior to infection.

Disease was monitored daily and scored as follows: 0 , no disease; 1 , mild erythema; 2 , hair loss around genitalia and appearance of sores; 3 , hunched posture and ruffled fur; 4 , hindlimb paralysis; 5 , moribund (26).

Cytokine measurement. To measure cytokine secretion into the vaginal lumen, two $50-\mu \mathrm{L}$ washes with sterile PBS were collected using a pipette from each mouse just prior to infection and daily after infection. Washes were centrifuged to remove cells and mucus, and supernatants were snap-frozen on dry ice. ELISA was used to measure IFN- $\gamma$, IFN- $\lambda$ (R\&D), IFN- $\alpha$ (PBL Assay Science), and IFN- $\beta$ (BioLegend) according to the manufacturer's protocol.

Virus quantification. For titration of virus in the vaginal lumen, $50-\mu \mathrm{L}$ washes with sterile PBS were collected using a pipette and a sterile calginate swab and diluted in $950 \mu \mathrm{L}$ of $\mathrm{ABC}$ buffer $\left(0.5 \mathrm{mM} \mathrm{CaCl}{ }_{2}\right.$, $0.5 \mathrm{mM} \mathrm{MgCl}, 1 \%$ glucose, $1 \%$ FBS in PBS; Sigma-Aldrich). To measure viral burden in the ganglia, mice were perfused with a minimum of $15 \mathrm{~mL}$ of PBS after sedation with ketamine and xylazine. Five pairs of sacral and lumbar DRG were excised from each mouse and snap-frozen on dry ice. Ganglia were pulverized with a motorized pestle homogenizer in $100 \mu \mathrm{L}$ of $\mathrm{ABC}$ buffer and titered in a final volume of $1 \mathrm{~mL}$. Plaque assays were performed on Vero cells as described (26). To measure viral DNA in the ganglia, DNA was extracted from homogenized DRG using a DNeasy kit (Qiagen). Viral DNA was detected by qPCR using iTaq Universal Probes kit (Bio-Rad) using the following previously published primer/probes: forward, 5'-TCAGCGAGGATAACCTGGGA-3'; reverse, 5-GGGAGAGCGTACTTGCAGG-3', probe: 5'-/56-FAM/CCAGTCGTT/ZEN/TATCTTCACTAGCCGCAGGTA/3IABkFQ/-3' (Integrated DNA Technologies) (79). qPCR was performed on a CFX Connect Real Time system (Bio-Rad).

Tissue processing and flow cytometry. All tissues were harvested from animals sedated with ketamine and xylazine and thoroughly perfused with a minimum of $15 \mathrm{~mL}$ of PBS. Vaginas and draining iliac lymph 
nodes were processed as follows: tissue was cut into pieces and digested for 15 minutes at $37^{\circ} \mathrm{C}$ in $0.5 \mathrm{mg} /$ $\mathrm{mL}$ of Dispase II (Roche) in DPBS (MilliporeSigma). Tissues were then digested for 40 minutes (vagina) or 25 minutes (lymph node) at $37^{\circ} \mathrm{C}$ with $0.5 \mathrm{mg} / \mathrm{mL}$ Collagenase D (Roche) and $15 \mu \mathrm{g} / \mathrm{mL}$ DNase I (Roche) in RPMI media (Thermo Fisher Scientific) with $10 \%$ FBS. Totals of $50 \mu \mathrm{L}$ (vagina) or $30 \mu \mathrm{L}$ (lymph node) of sterile EDTA were added to each sample and incubated at $37^{\circ} \mathrm{C}$ for another 5 minutes. Tissues were then mechanically disrupted through a $70-\mu \mathrm{m}$ cell strainer into single cell suspension using a $3 \mathrm{~mL}$ syringe plunger. To measure IFN- $\gamma$ production, cell suspensions were incubated with $25 \mathrm{ng} / \mathrm{mL}$ PMA (MilliporeSigma) and $0.5 \mu \mathrm{g} / \mathrm{mL}$ ionomycin (MilliporeSigma) for 7 hours at $37^{\circ} \mathrm{C}$ in the presence of $5 \mu \mathrm{g} / \mathrm{mL}$ brefeldin A (MilliporeSigma). Intracellular staining was performed using the Cytofix/Cytoperm kit (BD Biosciences) or the True Nuclear Transcription Factor Buffer set (BioLegend). For cytokines, after surface staining, cells were fixed in fixation and permeabilization solution at room temperature (RT) for 20 minutes and then incubated with intracellular antibodies overnight in Perm Wash Buffer. For T-bet and granzyme B, after surface staining, cells were incubated in $1 \times$ Fix Buffer on ice for 30 minutes and incubated with intracellular antibodies in $1 \times$ Perm Wash (BD Biosciences) on ice for 1 hour. Cell counts were performed by adding Precision Count Beads (BioLegend) to samples prior to flow cytometric acquisition. Dead cells were excluded using the Fixable Aqua Dead Cell Stain kit (Molecular Probes). Numbers of cell subsets were calculated by multiplying the total live cell count by the frequency of each subset, as identified by flow cytometry. Tetramers were prepared with HSV gB protein peptide 498-505 (ABI Scientific) by the Center of Human Immunology and Immunotherapy Programs at Washington University and conjugated to streptavidin-APC (Invitrogen). Tetramer staining was performed at $37^{\circ} \mathrm{C}$ for 20 minutes in PBS with $2 \%$ FBS. The following antibodies were used for this study: CD3 (clone 145-2C11), CD4 (clone GK1.5 or RM4-4), CD8a (clone 53-6.7), CD8b.2 (clone 53-5.8), CD69 (clone H1.2F3), CD45.1 (clone A20), CD44 (clone IM7), CD19 (clone 1D3/CD19), IFN- $\gamma$ (clone XMG1.2), granzyme B (clone GB12), T-bet (clone 4B10), CD119 (clone 2E2), CD11c (clone N418), I-A/I-E (clone M5/114.15.2), CD11b (clone M1/70), CD103 (clone 2E7), CD86 (clone GL-1), Ly6G (clone 1A8), Ly6C (clone HK1.4), NK1.1 (clone PK136), NKp46 (clone 29A1.4), and Armenian hamster IgG isotype control (Supplemental Table 1). All antibodies were purchased from BioLegend, except for the CD119 and Armenian hamster isotype control antibodies, which were purchased from eBioscience. Samples were acquired on an LSR Fortessa (BD Biosciences) and analyzed by FlowJo (Tree Star Inc.).

Histology and immunofluroscence. All tissues were harvested from animals sedated with ketamine and xylazine and thoroughly perfused with a minimum of $15 \mathrm{~mL}$ of PBS and $20 \mathrm{~mL}$ of $4 \%$ paraformaldehyde. Tissues were embedded in paraffin and sectioned on a microtome at the Histology Core in the Developmental Biology department at Washington University. HSV infection was identified in sections using an anti-HSV antibody incubated overnight at $4^{\circ} \mathrm{C}$ (Dako, B0114) and a donkey anti-rabbit IgG-HRP antibody (Jackson ImmunoResearch, 711-036-15) incubated for 1 hour at RT, and it was then enzymatically visualized by 3,3'-diaminobenzidine (DAB) enzyme reaction (Sigma-Aldrich). Sections were counterstained with H\&E, and images were captured on a Zeiss Cell Observer inverted microscope with color camera. For immunofluorescent visualization of $\mathrm{NK}$ cells, $\mathrm{Ncr} 1^{\mathrm{mT} / \mathrm{mG}}$ mice were perfused with PBS and PLP fixative with $2 \%$ paraformaldehyde. Tissues were cryoprotected overnight in 30\% sucrose, frozen in OCT, and cut on a cryostat as $7-\mu \mathrm{m}$ sections. Sections were incubated with a primary anti-HSV antibody for 1 hour at RT (Dako), a secondary donkey anti-rabbit IgG antibody conjugated to Alexa Fluor 647 (Molecular Probes) for 1 hour at RT, and DAPI as a nuclear counterstain. Images were captured on a Zeiss Cell Observer inverted microscope with color camera. NK cells were quantified using ImageJ software (NIH). Briefly, each image was divided into a grid of 400 pixel squares (Supplemental Figure 11). Squares that fell over infected areas, as denoted by HSV-antigen positivity, were marked, and $\mathrm{GFP}^{+}$NK cells that fell within those infected areas were counted. To quantify NK cells outside infected epithelium, regions of lamina propria or epithelium that were within 12,000 pixels (3 squares) were considered to be proximal areas, and $\mathrm{GFP}^{+} \mathrm{NK}$ cells that fell within those squares were counted. Total $\mathrm{NK}$ cell counts were then divided by total number of squares involved to obtain a frequency of NK cells/400 pixels squares.

Statistics. All data analysis was performed on Graphpad Prism8 software. Values were transformed by $\log _{10}$ to normalize distribution and variances. Viral titers were analyzed by 2-way ANOVA with a Bonferroni post hoc test to correct for multiple comparisons, an unpaired 2-tailed Student's $t$ test, or a Mann-Whitney $U$ test for nonnormally distributed data. Kruskal-Wallis and Dunn's multiple comparisons tests were used for ordinal disease score data. Cell number data was analyzed by 2-way ANOVA with Bonferroni post hoc test to correct for multiple comparisons or 1-way ANOVA with Tukey's post hoc test to correct for multiple comparisons. All data show mean \pm SD. $P<0.05$ was considered statistically significant. 
Study approval. This study was carried out in accordance with the recommendations in the Guide for the Care and Use of Laboratory Animals (National Academies Press, 2011). The protocols were approved by the IACUC at the Washington University School of Medicine (assurance no. A3381-01). All efforts were made to minimize animal suffering. All animal experiments were performed under biosafety level 2 (BSL2) containment.

\section{Author contributions}

AGL, MRF, and XJ conducted experiments, acquired, and analyzed data. JMS conducted experiments and acquired data. MJM helped design experiments, and DKS, MTB, and WMY provided key reagents and helped design experiments. HS designed experiments, acquired data, and analyzed data. HS wrote the manuscript, and all authors edited the final version.

\section{Acknowledgments}

We thank Adjoa Cofie for technical assistance, and we thank Michael Diamond and Akiko Iwasaki for critical review of the manuscript. This research was supported by funding from the NIH (AI134962). AGL is supported by funding for the Training Program in Immunology from the NIH (T32 AI007163).

Address correspondence to: Haina Shin, 660 South Euclid Street, Box 8051, St. Louis, Missouri 63110, USA. Phone: 317.747.3888; Email: haina.shin@wustl.edu.

MRF's present address is: Department of Molecular and Clinical Cancer Medicine, Northwest Cancer Research Centre, University of Liverpool, Lverpool, United Kingdom.

1. Looker KJ, Garnett GP, Schmid GP. An estimate of the global prevalence and incidence of herpes simplex virus type 2 infection. Bull World Health Organ. 2008;86(10):805-812.

2. Lafferty WE, Downey L, Celum C, Wald A. Herpes simplex virus type 1 as a cause of genital herpes: impact on surveillance and prevention. J Infect Dis. 2000;181(4):1454-1457.

3. Lavery HA, Connolly JH, Russell JD. Incidence of herpes genitalis in Northern Ireland in 1973-83 and herpes simplex types 1 and 2 isolated in 1982-4. Genitourin Med. 1986;62(1):24-27.

4. Langenberg AG, Corey L, Ashley RL, Leong WP, Straus SE. A prospective study of new infections with herpes simplex virus type 1 and type 2. Chiron HSV Vaccine Study Group. N Engl J Med. 1999;341(19):1432-1438.

5. Reeves WC, Corey L, Adams HG, Vontver LA, Holmes KK. Risk of recurrence after first episodes of genital herpes. Relation to HSV type and antibody response. N Engl J Med. 1981;305(6):315-319.

6. Lafferty WE, Coombs RW, Benedetti J, Critchlow C, Corey L. Recurrences after oral and genital herpes simplex virus infection. Influence of site of infection and viral type. N Engl J Med. 1987;316(23):1444-1449.

7. Engelberg R, Carrell D, Krantz E, Corey L, Wald A. Natural history of genital herpes simplex virus type 1 infection. Sex Transm Dis. 2003;30(2):174-177.

8. Richards JT, Kern ER, Overall JC, Glasgow LA. Differences in neurovirulence among isolates of Herpes simplex virus types 1 and 2 in mice using four routes of infection. J Infect Dis. 1981;144(5):464-471.

9. Zheng M, Conrady CD, Ward JM, Bryant-Hudson KM, Carr DJ. Comparison of the host immune response to herpes simplex virus 1 (HSV-1) and HSV-2 at two different mucosal sites. J Virol. 2012;86(13):7454-7458.

10. Stanberry LR, Kern ER, Richards JT, Overall JC. Recurrent genital herpes simplex virus infection in guinea pigs. Intervirology. 1985;24(4):226-231

11. Lekstrom-Himes JA, Pesnicak L, Straus SE. The quantity of latent viral DNA correlates with the relative rates at which herpes simplex virus types 1 and 2 cause recurrent genital herpes outbreaks. J Virol. 1998;72(4):2760-2764.

12. Maggioncalda J, Mehta A, Su YH, Fraser NW, Block TM. Correlation between herpes simplex virus type 1 rate of reactivation from latent infection and the number of infected neurons in trigeminal ganglia. Virology. 1996;225(1):72-81.

13. Sawtell NM, Thompson RL, Stanberry LR, Bernstein DI. Early intervention with high-dose acyclovir treatment during primary herpes simplex virus infection reduces latency and subsequent reactivation in the nervous system in vivo. J Infect Dis. 2001;184(8):964-971.

14. Hoshino Y, Pesnicak L, Cohen JI, Straus SE. Rates of reactivation of latent herpes simplex virus from mouse trigeminal ganglia ex vivo correlate directly with viral load and inversely with number of infiltrating CD8+ T cells. $J$ Virol. 2007;81(15):8157-8164 .

15. Zhu J, et al. Virus-specific CD8+ T cells accumulate near sensory nerve endings in genital skin during subclinical HSV-2 reactivation. J Exp Med. 2007;204(3):595-603.

16. Zhu J, et al. Immune surveillance by CD8 $\alpha \alpha+$ skin-resident $\mathrm{T}$ cells in human herpes virus infection. Nature. 2013;497(7450):494-497.

17. Posavad CM, et al. Enrichment of herpes simplex virus type 2 (HSV-2) reactive mucosal $\mathrm{T}$ cells in the human female genital tract. Mucosal Immunol. 2017;10(5):1259-1269.

18. Schiffer JT, et al. Mucosal host immune response predicts the severity and duration of herpes simplex virus-2 genital tract shedding episodes. Proc Natl Acad Sci USA. 2010;107(44):18973-18978.

19. Bernstein DI, et al. Successful application of prime and pull strategy for a therapeutic HSV vaccine. NPJ Vaccines. 2019;4:33

20. Koelle DM, Posavad CM, Barnum GR, Johnson ML, Frank JM, Corey L. Clearance of HSV-2 from recurrent genital lesions 
correlates with infiltration of HSV-specific cytotoxic T lymphocytes. J Clin Invest. 1998;101(7):1500-1508.

21. Iijima N, et al. Dendritic cells and B cells maximize mucosal Th1 memory response to herpes simplex virus. J Exp Med. 2008;205(13):3041-3052.

22. Iijima N, Iwasaki A. T cell memory. A local macrophage chemokine network sustains protective tissue-resident memory CD4 T cells. Science. 2014;346(6205):93-98.

23. Milligan GN, Bernstein DI, Bourne N. T lymphocytes are required for protection of the vaginal mucosae and sensory ganglia of immune mice against reinfection with herpes simplex virus type 2. J Immunol. 1998;160(12):6093-6100.

24. Harandi AM, Svennerholm B, Holmgren J, Eriksson K. Differential roles of B cells and IFN-gamma-secreting CD4(+) T cells in innate and adaptive immune control of genital herpes simplex virus type 2 infection in mice. J Gen Virol. 2001;82(Pt 4):845-853.

25. Iijima N, Iwasaki A. Access of protective antiviral antibody to neuronal tissues requires CD4 T-cell help. Nature. 2016;533(7604):552-556.

26. Shin H, Iwasaki A. A vaccine strategy that protects against genital herpes by establishing local memory T cells. Nature. 2012;491(7424):463-467.

27. Liu T, Khanna KM, Chen X, Fink DJ, Hendricks RL. CD8(+) T cells can block herpes simplex virus type 1 (HSV-1) reactivation from latency in sensory neurons. J Exp Med. 2000;191(9):1459-1466.

28. Khanna KM, Bonneau RH, Kinchington PR, Hendricks RL. Herpes simplex virus-specific memory CD8+ T cells are selectively activated and retained in latently infected sensory ganglia. Immunity. 2003;18(5):593-603.

29. Knickelbein JE, Khanna KM, Yee MB, Baty CJ, Kinchington PR, Hendricks RL. Noncytotoxic lytic granule-mediated CD8+ T cell inhibition of HSV-1 reactivation from neuronal latency. Science. 2008;322(5899):268-271.

30. Kaushic C, Ashkar AA, Reid LA, Rosenthal KL. Progesterone increases susceptibility and decreases immune responses to genital herpes infection. J Virol. 2003;77(8):4558-4565.

31. Wang H, Davido DJ, Morrison LA. HSV-1 strain McKrae is more neuroinvasive than HSV-1 KOS after corneal or vaginal inoculation in mice. Virus Res. 2013;173(2):436-440.

32. Watson G, et al. Sequence and comparative analysis of the genome of HSV-1 strain McKrae. Virology. 2012;433(2):528-537.

33. Acton SE, et al. Dendritic cells control fibroblastic reticular network tension and lymph node expansion. Nature. 2014;514(7523):498-502.

34. Iwasaki A, Medzhitov R. Regulation of adaptive immunity by the innate immune system. Science. 2010;327(5963):291-295.

35. Durai V, Murphy KM. Functions of Murine Dendritic Cells. Immunity. 2016;45(4):719-736.

36. Khan S, et al. Dampened antiviral immunity to intravaginal exposure to RNA viral pathogens allows enhanced viral replication. J Exp Med. 2016;213(13):2913-2929.

37. Iversen MB, et al. An innate antiviral pathway acting before interferons at epithelial surfaces. Nat Immunol. 2016;17(2):150-158.

38. Ye L, Schnepf D, Staeheli P. Interferon- $\lambda$ orchestrates innate and adaptive mucosal immune responses. Nat Rev Immunol. 2019;19(10):614-625.

39. Milligan GN, Bernstein DI. Interferon-gamma enhances resolution of herpes simplex virus type 2 infection of the murine genital tract. Virology. 1997;229(1):259-268.

40. Nakanishi Y, Lu B, Gerard C, Iwasaki A. CD8(+) T lymphocyte mobilization to virus-infected tissue requires CD4(+) T-cell help. Nature. 2009;462(7272):510-513.

41. Gill N, Chenoweth MJ, Verdu EF, Ashkar AA. NK cells require type I IFN receptor for antiviral responses during genital HSV-2 infection. Cell Immunol. 2011;269(1):29-37.

42. Sojka DK, Yang L, Plougastel-Douglas B, Higuchi DA, Croy BA, Yokoyama WM. Cutting Edge: Local Proliferation of Uterine Tissue-Resident NK Cells during Decidualization in Mice. J Immunol. 2018;201(9):2551-2556.

43. Mueller SN, Heath W, McLain JD, Carbone FR, Jones CM. Characterization of two TCR transgenic mouse lines specific for herpes simplex virus. Immunol Cell Biol. 2002;80(2):156-163.

44. Shin H, Kumamoto Y, Gopinath S, Iwasaki A. CD301b+ dendritic cells stimulate tissue-resident memory CD8+ T cells to protect against genital HSV-2. Nat Commun. 2016;7:13346.

45. Liu T, Khanna KM, Carriere BN, Hendricks RL. Gamma interferon can prevent herpes simplex virus type 1 reactivation from latency in sensory neurons. J Virol. 2001;75(22):11178-11184.

46. Hasegawa H, Abbott S, Han BX, Qi Y, Wang F. Analyzing somatosensory axon projections with the sensory neuron-specific Advillin gene. J Neurosci. 2007;27(52):14404-14414.

47. Zhou X, et al. Deletion of PIK3C3/Vps34 in sensory neurons causes rapid neurodegeneration by disrupting the endosomal but not the autophagic pathway. Proc Natl Acad Sci USA. 2010;107(20):9424-9429.

48. Lee SH, et al. Identifying the initiating events of anti-Listeria responses using mice with conditional loss of IFN- $\gamma$ receptor subunit 1 (IFNGR1). J Immunol. 2013;191(8):4223-4234.

49. Thompson RL, Sawtell NM. Replication of herpes simplex virus type 1 within trigeminal ganglia is required for high frequency but not high viral genome copy number latency. J Virol. 2000;74(2):965-974

50. Macdonald SJ, Mostafa HH, Morrison LA, Davido DJ. Genome sequence of herpes simplex virus 1 strain McKrae. $J$ Virol. 2012;86(17):9540-9541.

51. Szpara ML, Parsons L, Enquist LW. Sequence variability in clinical and laboratory isolates of herpes simplex virus 1 reveals new mutations. J Virol. 2010;84(10):5303-5313.

52. Szpara ML, et al. Evolution and diversity in human herpes simplex virus genomes. J Virol. 2014;88(2):1209-1227.

53. Newman RM, et al. Genome Sequencing and Analysis of Geographically Diverse Clinical Isolates of Herpes Simplex Virus 2. J Virol. 2015;89(16):8219-8232.

54. Akhtar LN, et al. Genotypic and Phenotypic Diversity of Herpes Simplex Virus 2 within the Infected Neonatal Population. mSphere. 2019;4(1):e00590-18.

55. Inagaki-Ohara K, Daikoku T, Goshima F, Nishiyama Y. Impaired induction of protective immunity by highly virulent herpes simplex virus type 2 in a murine model of genital herpes. Arch Virol. 2000;145(10):1989-2002.

56. Kim M, et al. Herpes simplex virus antigens directly activate NK cells via TLR2, thus facilitating their presentation to CD4 T lymphocytes. J Immunol. 2012;188(9):4158-4170. 
57. Lee AJ, et al. Inflammatory monocytes require type I interferon receptor signaling to activate NK cells via IL-18 during a mucosal viral infection. J Exp Med. 2017;214(4):1153-1167.

58. Martín-Fontecha A, et al. Induced recruitment of NK cells to lymph nodes provides IFN-gamma for T(H)1 priming. Nat Immunol. 2004;5(12):1260-1265.

59. Matsuo M, et al. IFN-gamma enables cross-presentation of exogenous protein antigen in human Langerhans cells by potentiating maturation. Proc Natl Acad Sci USA. 2004;101(40):14467-14472.

60. Bosnjak L, Miranda-Saksena M, Koelle DM, Boadle RA, Jones CA, Cunningham AL. Herpes simplex virus infection of human dendritic cells induces apoptosis and allows cross-presentation via uninfected dendritic cells. J Immunol. 2005;174(4):2220-2227.

61. Kruse M, et al. Mature dendritic cells infected with herpes simplex virus type 1 exhibit inhibited T-cell stimulatory capacity. J Virol. 2000;74(15):7127-7136

62. Stefanidou M, et al. Herpes simplex virus 2 (HSV-2) prevents dendritic cell maturation, induces apoptosis, and triggers release of proinflammatory cytokines: potential links to HSV-HIV synergy. J Virol. 2013;87(3):1443-1453.

63. Allan RS, et al. Migratory dendritic cells transfer antigen to a lymph node-resident dendritic cell population for efficient CTL priming. Immunity. 2006;25(1):153-162.

64. Zhao X, et al. Vaginal submucosal dendritic cells, but not Langerhans cells, induce protective Th1 responses to herpes simplex virus-2. J Exp Med. 2003;197(2):153-162.

65. Lee HK, et al. Differential roles of migratory and resident DCs in T cell priming after mucosal or skin HSV-1 infection. J Exp Med. 2009;206(2):359-370.

66. Mueller SN, Jones CM, Smith CM, Heath WR, Carbone FR. Rapid cytotoxic T lymphocyte activation occurs in the draining lymph nodes after cutaneous herpes simplex virus infection as a result of early antigen presentation and not the presence of virus. J Exp Med. 2002;195(5):651-656.

67. Shin H, Iwasaki A. Generating protective immunity against genital herpes. Trends Immunol. 2013;34(10):487-494.

68. Schiffer JT, Swan DA, Prlic M, Lund JM. Herpes simplex virus-2 dynamics as a probe to measure the extremely rapid and spatially localized tissue-resident T-cell response. Immunol Rev. 2018;285(1):113-133.

69. Yordy B, Iijima N, Huttner A, Leib D, Iwasaki A. A neuron-specific role for autophagy in antiviral defense against herpes simplex virus. Cell Host Microbe. 2012;12(3):334-345.

70. Su C, Zhan G, Zheng C. Evasion of host antiviral innate immunity by HSV-1, an update. Virol J. 2016;13:38.

71. Koyanagi N, et al. Herpes simplex virus-1 evasion of CD8+ T cell accumulation contributes to viral encephalitis. J Clin Invest. 2017;127(10):3784-3795.

72. Orr MT, Mathis MA, Lagunoff M, Sacks JA, Wilson CB. CD8 T cell control of HSV reactivation from latency is abrogated by viral inhibition of MHC class I. Cell Host Microbe. 2007;2(3):172-180.

73. Khoury-Hanold W, et al. Viral Spread to Enteric Neurons Links Genital HSV-1 Infection to Toxic Megacolon and Lethality. Cell Host Microbe. 2016;19(6):788-799.

74. Rosato PC, Leib DA. Neuronal Interferon Signaling Is Required for Protection against Herpes Simplex Virus Replication and Pathogenesis. PLoS Pathog. 2015;11(7):e1005028.

75. Song R, Koyuncu OO, Greco TM, Diner BA, Cristea IM, Enquist LW. Two Modes of the Axonal Interferon Response Limit Alphaherpesvirus Neuroinvasion. mBio. 2016;7(1):e02145-e02115.

76. Baldridge MT, et al. Expression of Ifnlr1 on Intestinal Epithelial Cells Is Critical to the Antiviral Effects of Interferon Lambda against Norovirus and Reovirus. J Virol. 2017;91(7):e02079-16.

77. Williams LE, Nesburn AB, Kaufman HE. EXPERIMENTAL INDUCTION OF DISCIFORM KERATITIS. Arch Ophthalmol. $1965 ; 73: 112-114$.

78. Spang AE, Godowski PJ, Knipe DM. Characterization of herpes simplex virus 2 temperature-sensitive mutants whose lesions map in or near the coding sequences for the major DNA-binding protein. J Virol. 1983;45(1):332-342.

79. Hoshino Y, et al. Comparative efficacy and immunogenicity of replication-defective, recombinant glycoprotein, and DNA vaccines for herpes simplex virus 2 infections in mice and guinea pigs. $J$ Virol. 2005;79(1):410-418. 